\title{
Topographic classification of the thalamus surfaces related to microneurosurgery: a white matter fiber microdissection study
}

\author{
Serra, Carlo ; Türe, Uğur ; Krayenbühl, Niklaus ; Şengül, Gülgün ; Yaşargil, Dianne C H ; Yaşargil, M \\ Gazi
}

\begin{abstract}
OBJECTIVE To describe the topographic anatomy of surgically accessible surfaces of the human thalamus as a guide to surgical exploration of this sensitive area. METHODS Using the operating microscope, we applied the fiber microdissection technique to study 10 brain specimens. Step-by-step dissections in superior-inferior, medial-lateral, and posterior-anterior directions were conducted to expose the surfaces and nuclei of the thalamus and to investigate the relevant anatomic relationships and visible connections. RESULTS There were 4 distinct free surfaces of the thalamus identified: lateral ventricle surface, velar surface, cisternal surface, and third ventricle surface. Each is described with reference to recognizable anatomic landmarks and to the underlying thalamic nuclei. The neural structures most commonly encountered during the surgical approach to each individual surface are highlighted and described. CONCLUSIONS Observations from this study supplement current knowledge, advancing the capabilities to define the exact topographic location of thalamic lesions. This improved understanding of anatomy is valuable when designing the most appropriate and least traumatic surgical approach to thalamic lesions. These proposed surface divisions, based on recognizable anatomic landmarks, can provide more reliable surgical orientation.
\end{abstract}

DOI: https://doi.org/10.1016/j.wneu.2016.09.101

Posted at the Zurich Open Repository and Archive, University of Zurich

ZORA URL: https://doi.org/10.5167/uzh-133784

Journal Article

Accepted Version

Originally published at:

Serra, Carlo; Türe, Uğur; Krayenbühl, Niklaus; Şengül, Gülgün; Yaşargil, Dianne C H; Yaşargil, M Gazi (2017). Topographic classification of the thalamus surfaces related to microneurosurgery: a white matter fiber microdissection study. World Neurosurgery, 97:438-452.

DOI: https://doi.org/10.1016/j.wneu.2016.09.101 


\section{elsevier_WNEU_4641}

\section{Original Article}

Short title: TOPOGRAPHIC ANATOMY OF THE THALAMUS

\section{Topographic Classification of the Thalamic Surfaces Related to Microneurosurgery: A White Matter Fiber Microdissection Study}

Carlo Serra',

Uğur Türe', *

drture@yahoo.com

Niklaus Krayenbühl²

Gülgün Șengül

Dianne C.H. Yaşargil

M. Gazi Yaşargil'

'Department of Neurosurgery, Yeditepe University School of Medicine, Istanbul, Turkey

2Department of Neurosurgery, UniversitätsSpital Zürich, Zürich, Switzerland

${ }^{3}$ Department of Anatomy, Ege University School of Medicine, izmir, Turkey

*To whom correspondence should be addressed: Uğur Türe, M.D.

Conflict of interest statement: This work was supported by Mr. Zafer Emre Memecan.

\section{Objective}

To describe the topographic anatomy of surgically accessible surfaces of the human thalamus as a guide to surgical exploration of this sensitive area.

\section{Methods}

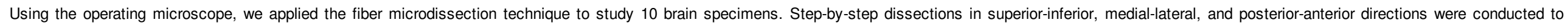
expose the surfaces and nuclei of the thalamus and to investigate the relevant anatomic relationships and visible connections.

Results

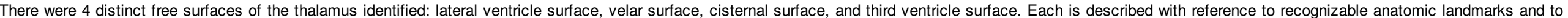
the underlying thalamic nuclei. The neural structures most commonly encountered during the surgical approach to each individual surface are highlighted and described.

Conclusions

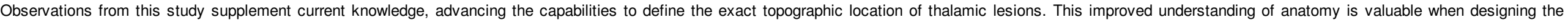
most appropriate and least traumatic surgical approach to thalamic lesions. These proposed surface divisions, based on recognizable anatomic landmarks, can provide more reliable surgical orientation.

Key words: Anatomy; Fiber microdissection; Thalamic peduncles; Thalamus; White matter

\section{Introduction}

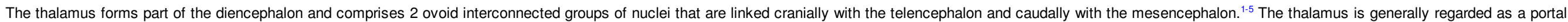

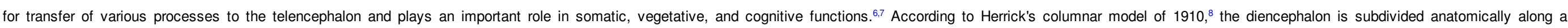




\section{elsevier_WNEU_4641}

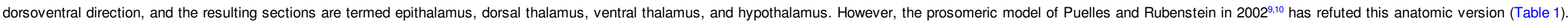

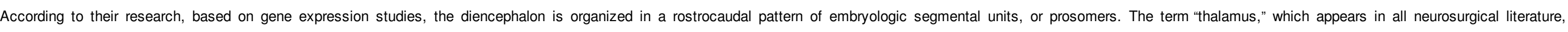
corresponds to the main groups of nuclei enclosed within the external medullary lamina.

Table 1 Comparison of Columnar and Prosomeric Models

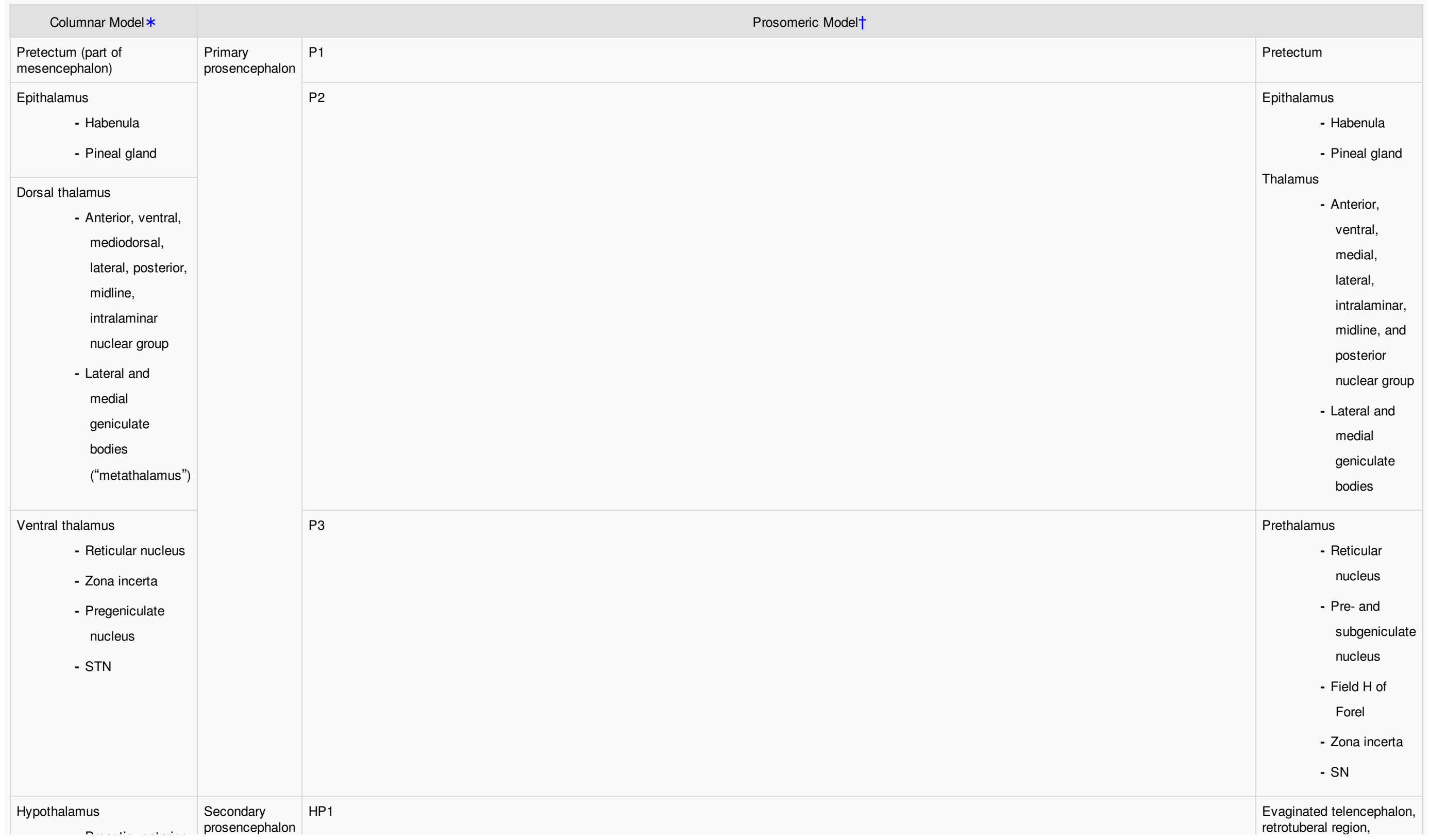




\section{elsevier_WNEU_4641}

- rreopic, anterior,

tuberal,

mammillary

region

Telencephalon

STN, subthalamic nucleus; $S N$, substantia nigra.

* Adapted from Herrick CJ. The morphology of the forebrain in amphibia and reptilia. Journal of Comparative Neurology and Psychology. 1910;20:413-547. ${ }^{8}$

${ }^{\dagger}$ Adapted from Puelles L, Rubenstein JL. Forebrain gene expression domains and the evolving prosomeric model. Trends Neurosci. 2003;26:469-476. ${ }^{9}$

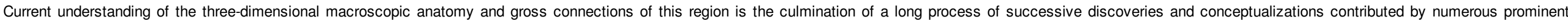

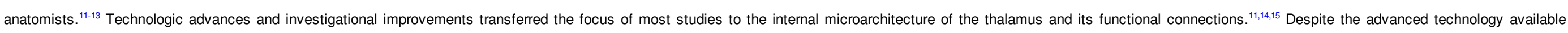

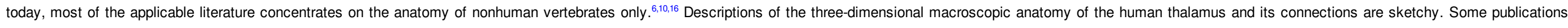

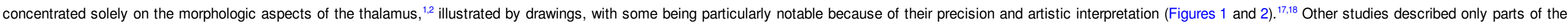
diencephalon, often incidentally in the context of studies dedicated to other anatomic or surgical topics. ${ }^{19,20}$




B

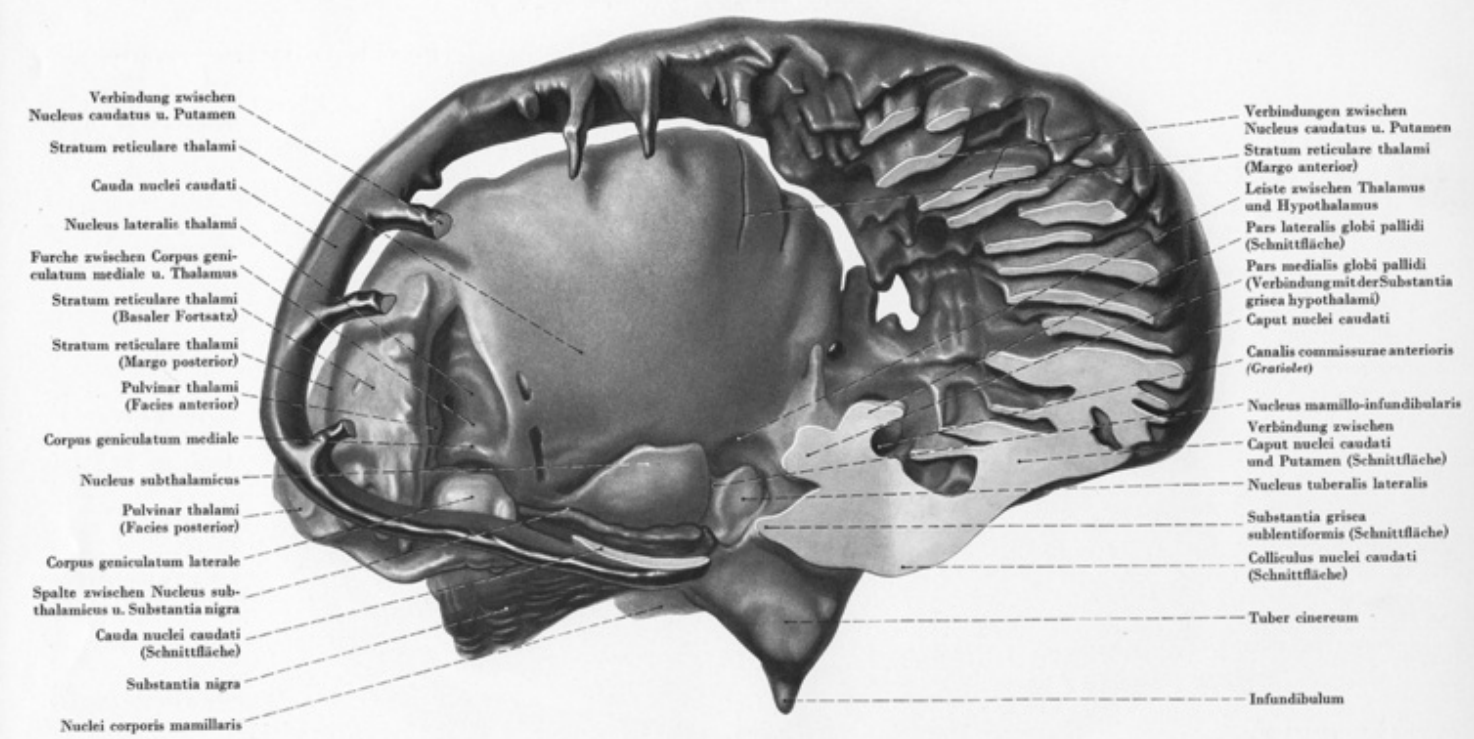

Asb. 75. Lateralo Ansicht des Modells nach Eutternung des Nuclews kentilormin, des Corpus amygdaloldeum und der Subtantia perforata anterior.

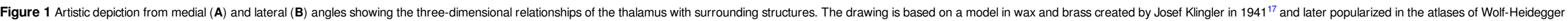
and Pernkopf. ${ }^{19}$

$\mathcal{E}$ The course of the conspicuous mammillothalamic tract on its way to the anterior thalamic nucleus enables a comparison of level and angle of this
with another series being studied. The corona is at its broadest because abundant motor and premotor axons are crowding into the capsule. Separatin 作 amocortical nibers medially, while laterally are descending premotor axons. It nections, proceeds more directly ventrally, and when passing by the sub conthalamus, is broken into fascicles by the strands of the lenticular fas. ciculus from the pallidus. On the lower surface of the diencephalon $s$ is the cerebral peduncle, composed at this level of the survivors
of the anterior capsular limb. In the thalamus, lateralis anterior has begun $(\mathrm{LA})$, and medially the group of small nuclei which wrap around the front of the incipient which croseses the midline submedius (Shm) median reuniens ralis (CL), paratenialis $(\mathrm{Pt}$ ), paraventricularis S., Ro) (St. M.). The massa intermedia is not a
(together with stia medullis. commissure, but a midline continuity
of cells. $\quad$ The paracentral cortex the projections of the arcuate nuce leus are shown, stemming from $\mathbf{G}$.
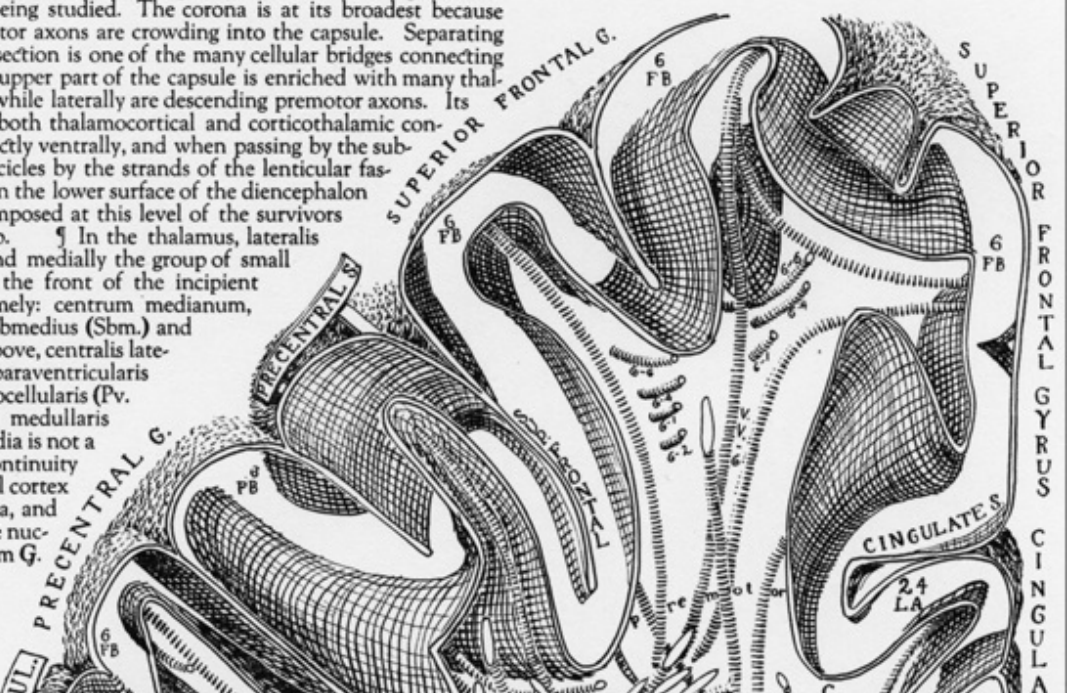


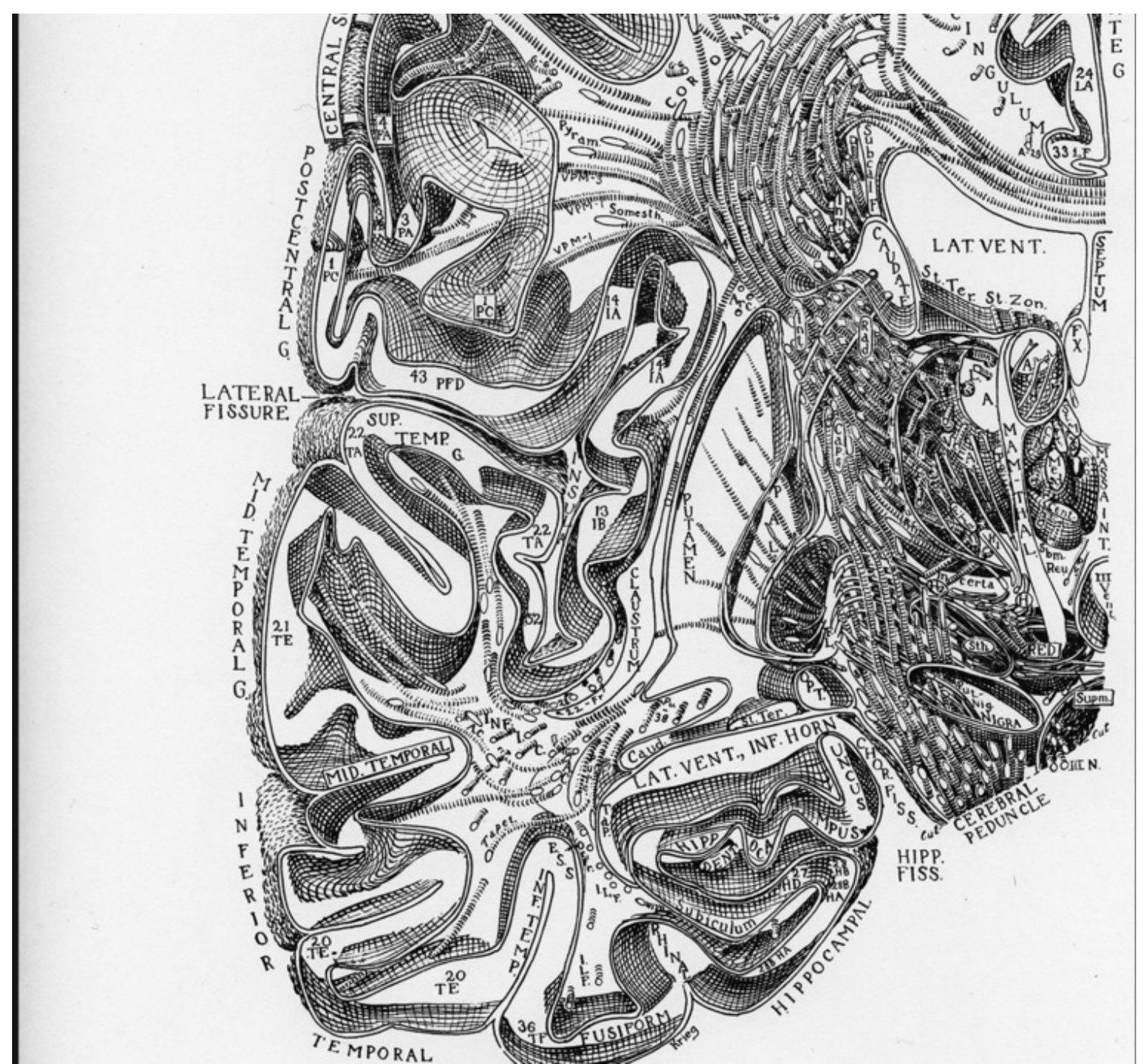

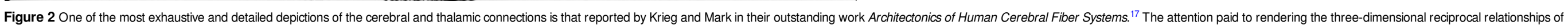
fiber tracts is remarkable; fiber tracts pertaining to the thalamic radiations are represented with square sections. The mammillothalamic tract running between the medial and lateral groups of nucle is also depicted.

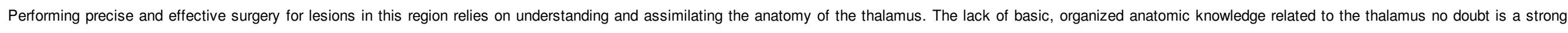

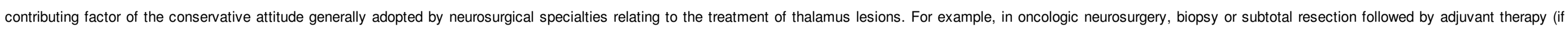
indicated) is often the favored approach, ${ }^{21-25}$ despite the awareness that radical tumor resection is an established and positive prognostic factor in the management of gliomas. ${ }^{26}$

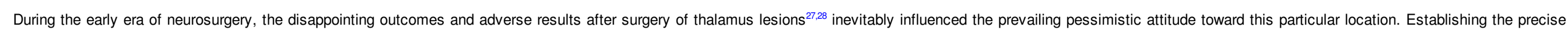

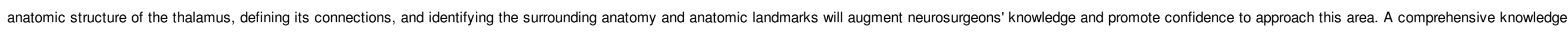

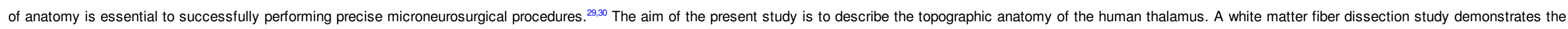
surfaces of the thalamus that are surgically accessible. In addition, the relationships of these surfaces to the thalamic nuclei, neighboring neural structures, and fiber tracts are highlighted. 


\section{Materials and Methods}

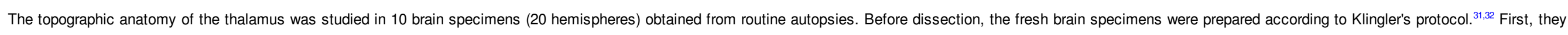

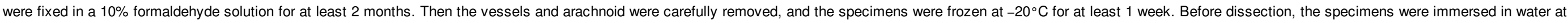

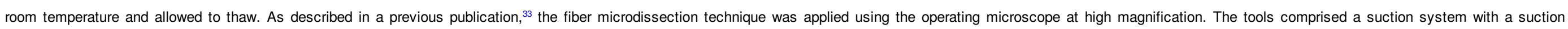

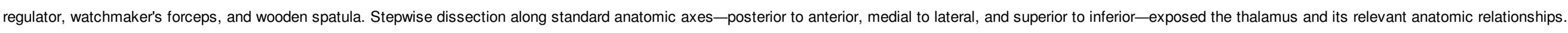

\section{Results}

\section{Superior Aspect}

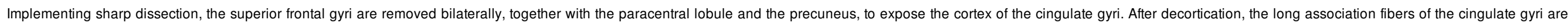

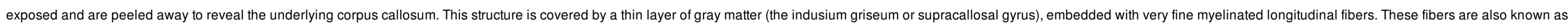

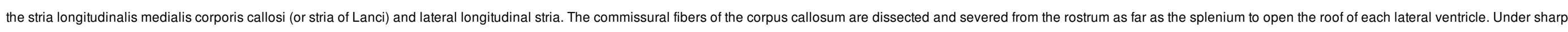

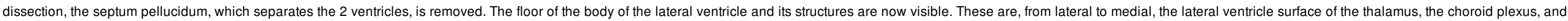
the fornix (Figure 3A).
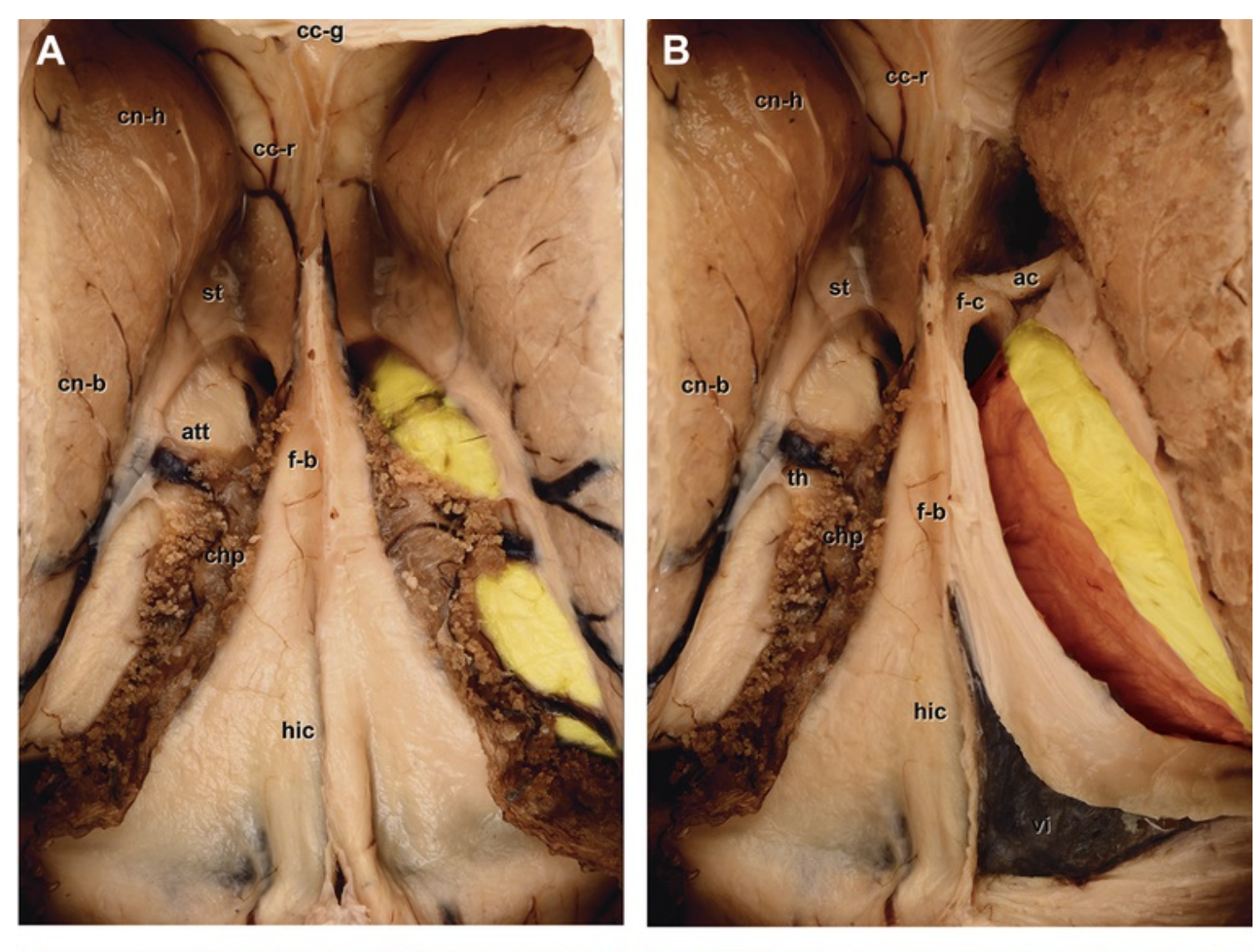


\section{elsevier_WNEU_4641}

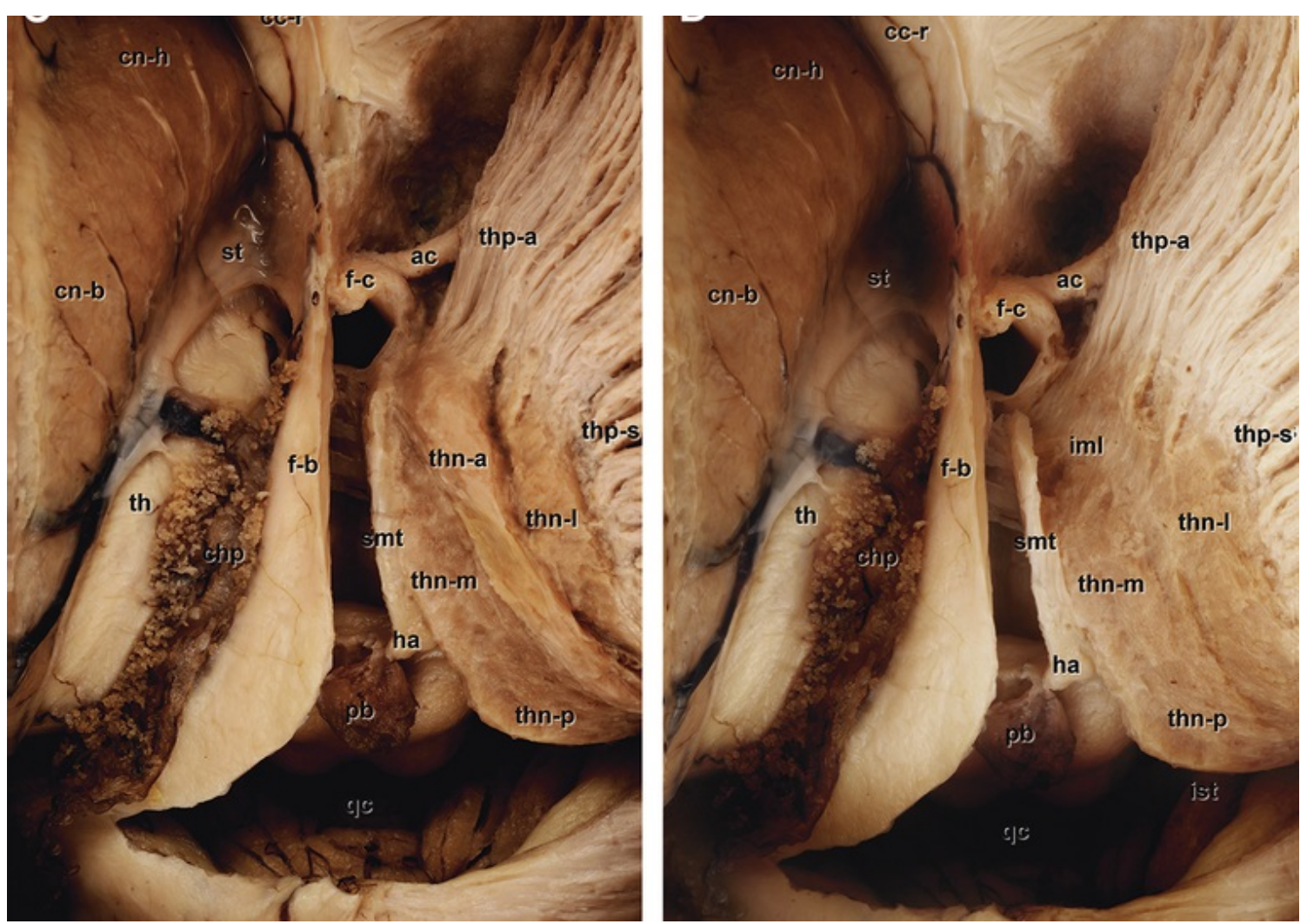

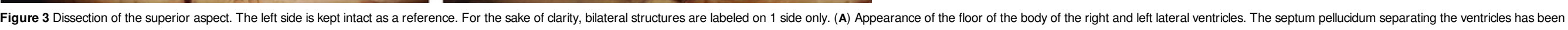

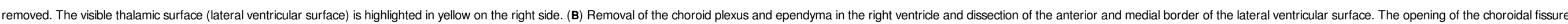

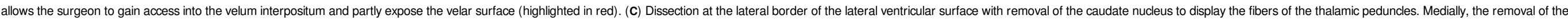

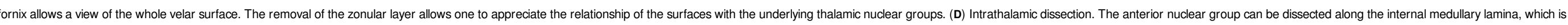

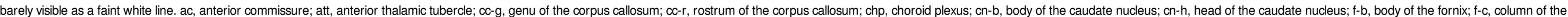

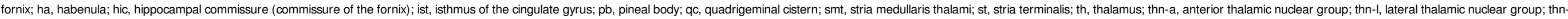
m, medial thalamic nuclear group; thn-p, posterior thalamic nuclear group; thp-a, anterior thalamic peduncle; thp-s, superior thalamic peduncle; thp-p, posterior thalamic peduncle; vi, velum interpositum.

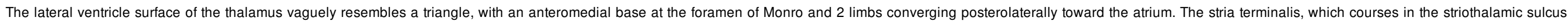

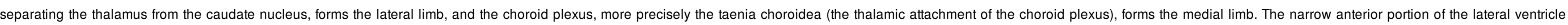
surface mostly corresponds to the anterior thalamic tubercle.

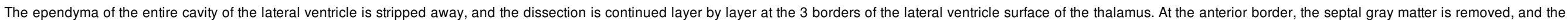

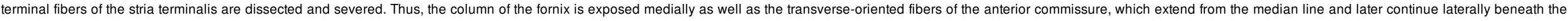
caudate nucleus into Gratiolet canal (Figure 3B).

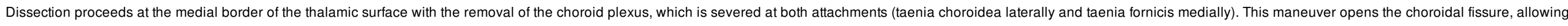

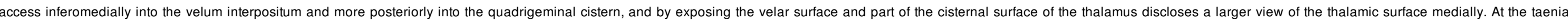

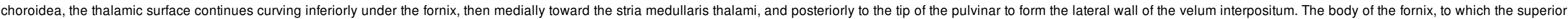




\section{elsevier_WNEU_4641}

tela choroidea is attached, forms the roof of the velum interpositum and prevents medial exposure of the thalamus (Figure 3B).

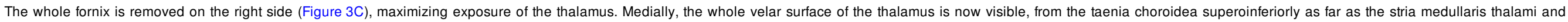

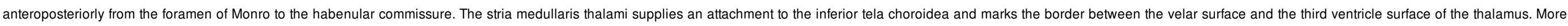
posteriorly, the whole superior surface of the pulvinar is also exposed together with the quadrigeminal cistern.

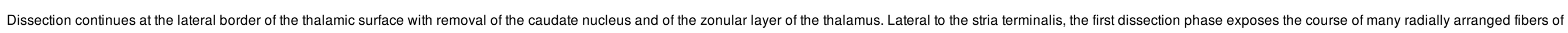

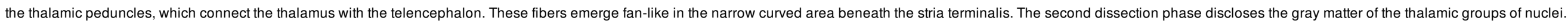

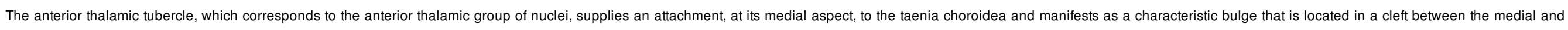

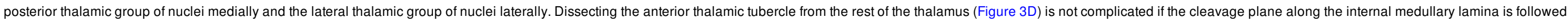

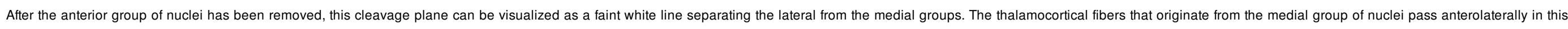
plane, between the lateral group of nuclei inferiorly and the anterior group of nuclei superiorly, to reach the internal capsule.

\section{Medial Aspect}

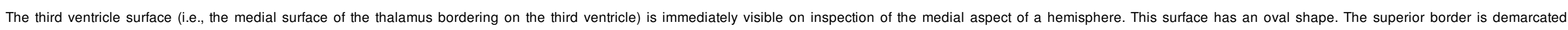

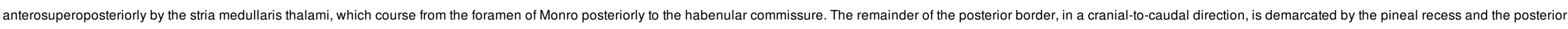
commissure. The inferior border is defined by the hypothalamic sulcus, a shallow groove originating from the superior limit of the cerebral aqueduct, just beneath the posterior commissure, culminating in the foramen of Monro.

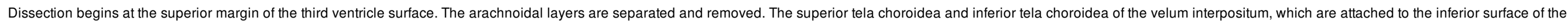

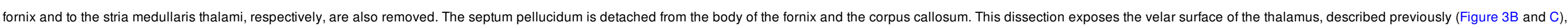
and the medial surface of the pulvinar, which is part of the cisternal surface (Figure 4A).
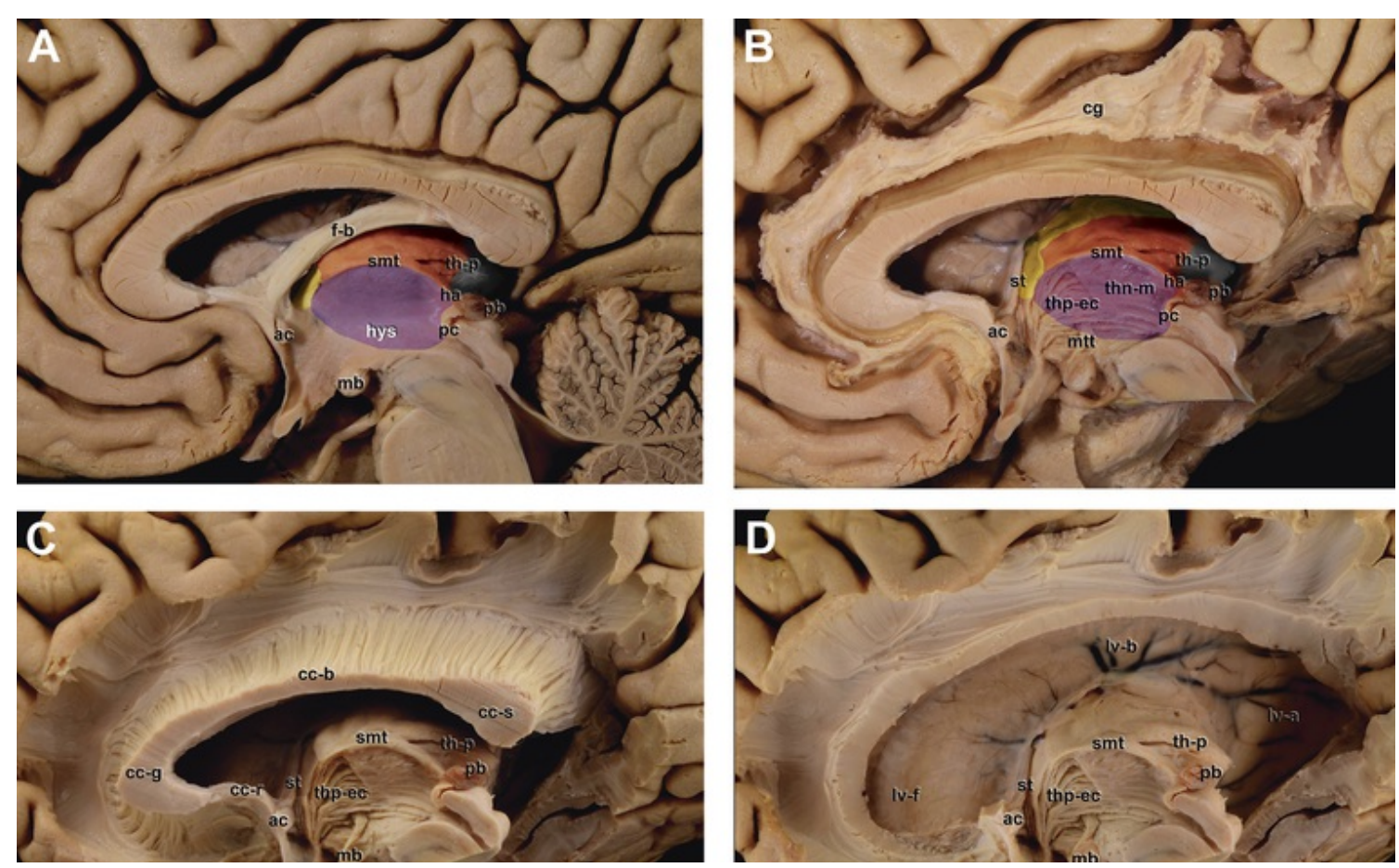

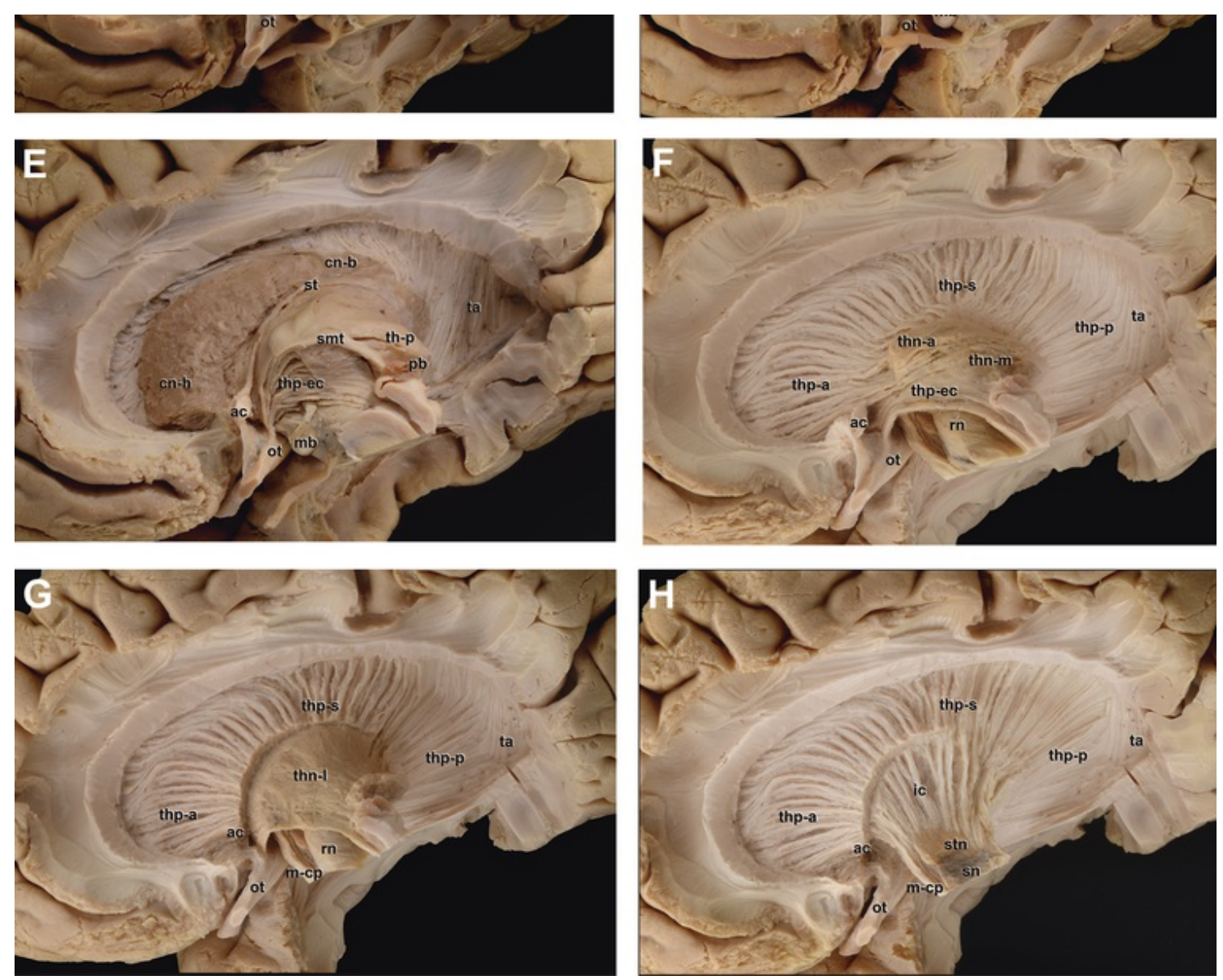

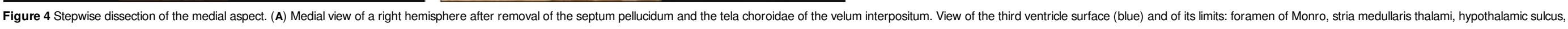

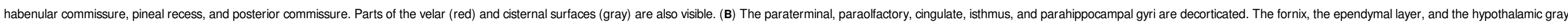

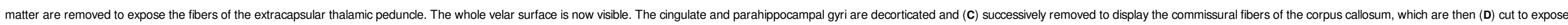

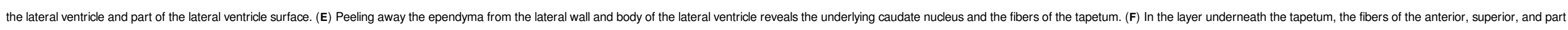

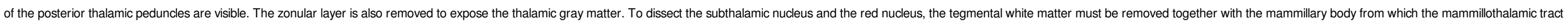

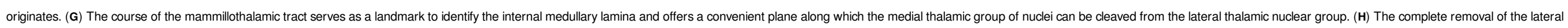

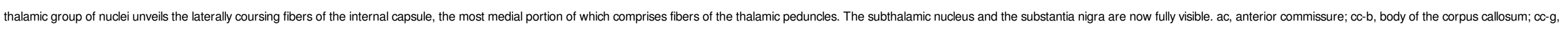

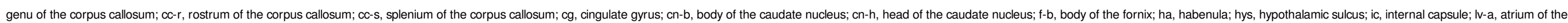

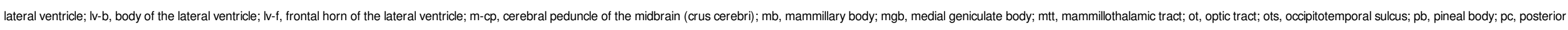

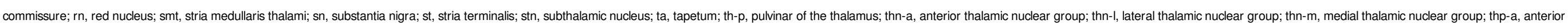
thalamic peduncle; thp-ec, extracapsular thalamic peduncle; thp-s, superior thalamic peduncle; thp-p, posterior thalamic peduncle.

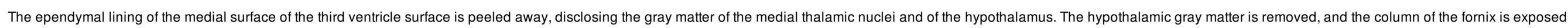

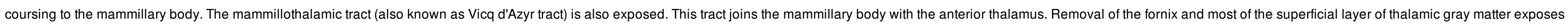




\section{elsevier_WNEU_4641}

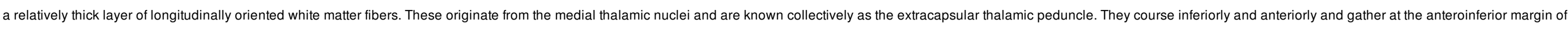
the thalamus at the border with the hypothalamus. Here they angle $90^{\circ}$ laterally, inferior to the anterior commissure, to enter the ansa peduncularis (Figure 4B).

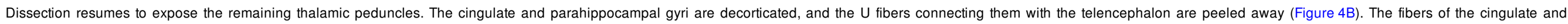

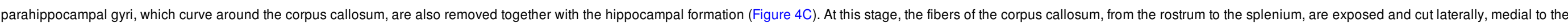

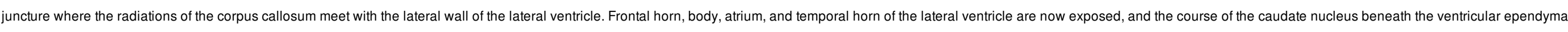
can be imagined (Figure 4D). The lateral ventricle surface of the thalamus is also visible.

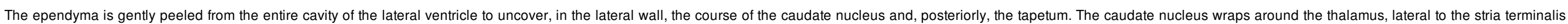

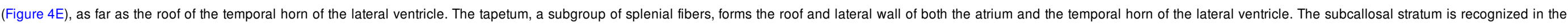
superior-lateral wall of the lateral ventricle, between the caudate nucleus and the callosal fibers.

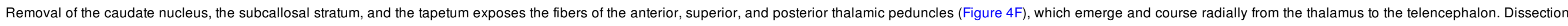

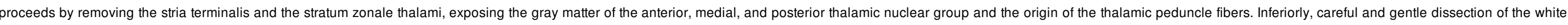

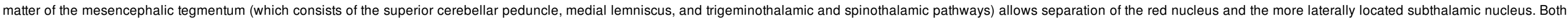
can be relatively clearly identified because of their firm consistency, which differentiates them from the surrounding white matter. Anterior to both of these nuclei, the craniocaudally directed fibers of the cerebral peduncle are dissected.

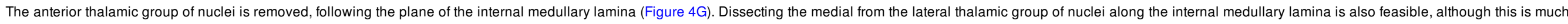

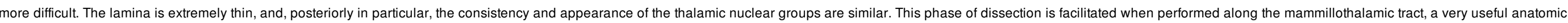
landmark that runs from the mammillary body up to the anterior group of nuclei, maintaining a course within the internal medullary lamina along its entire length.

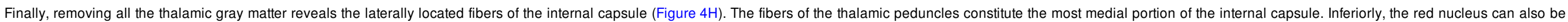

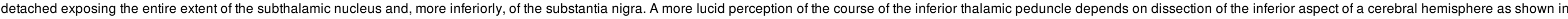

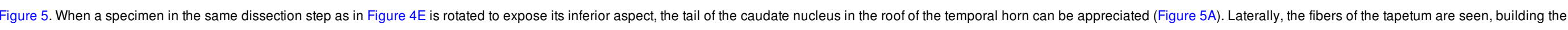

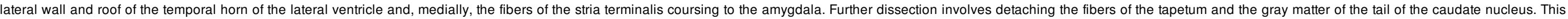

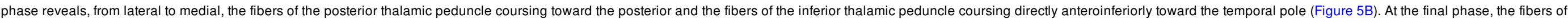
the stria terminalis are removed to display the entire course of the fibers of the inferior thalamic peduncle, which can be followed to their origin at the pulvinar (Figure $5 \mathrm{C}$ ). 

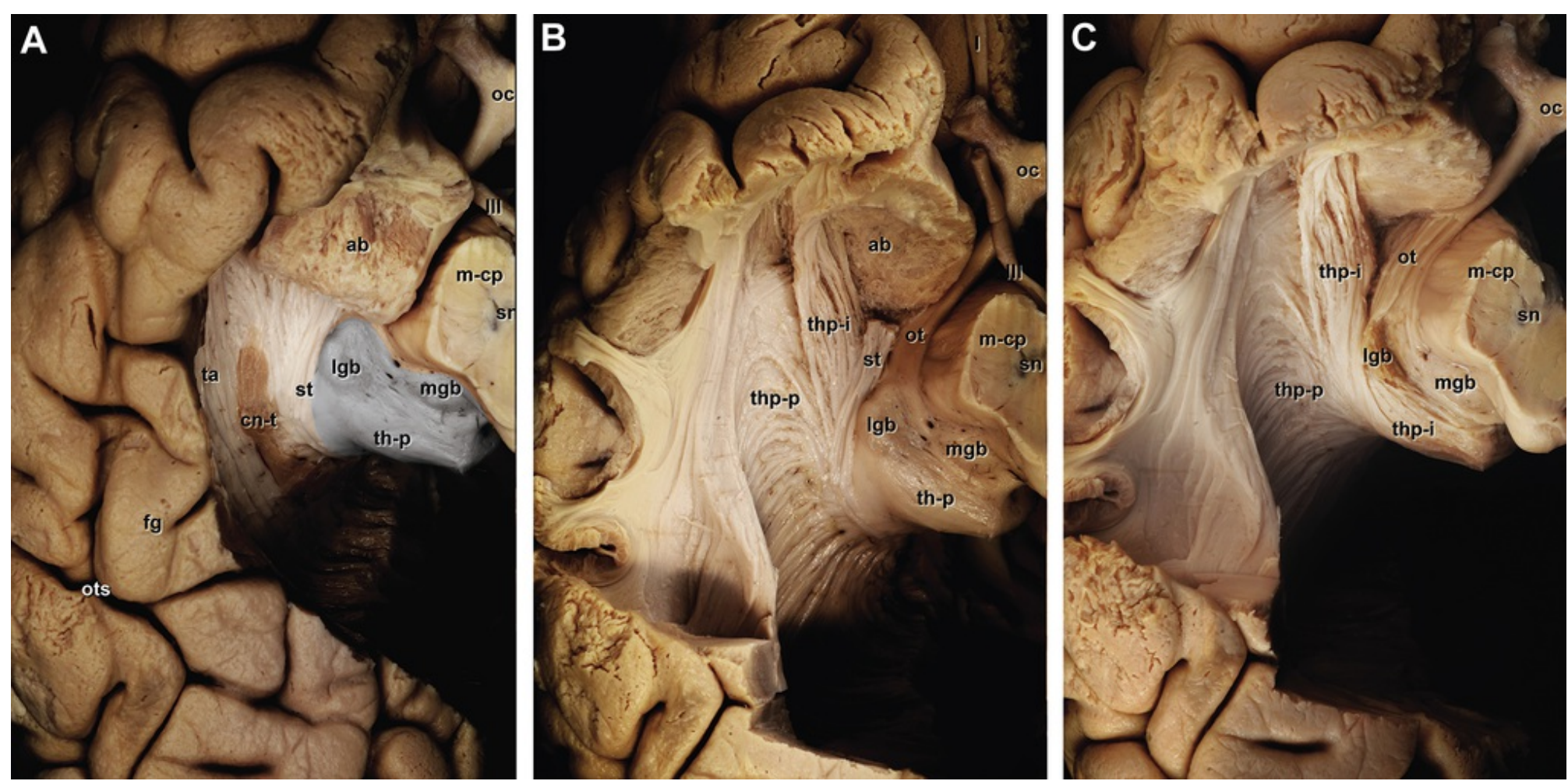

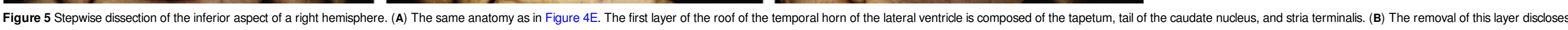

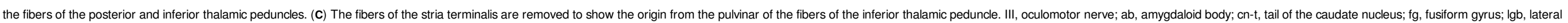

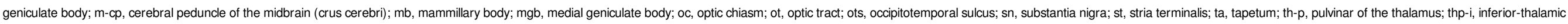
peduncle; thp-p, posterior thalamic peduncle.

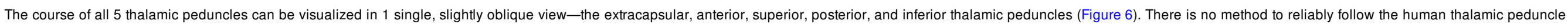

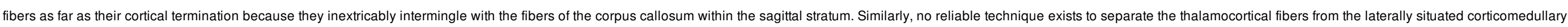

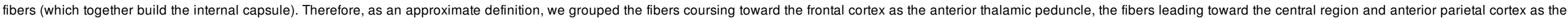

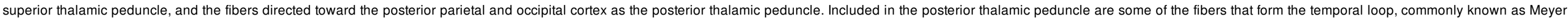
loop. ${ }^{34}$ The fibers radiating from the pulvinar and continuing to the tip of the temporal lobe (Figure $5 \mathrm{C}$ ) are part of the inferior thalamic peduncle. 


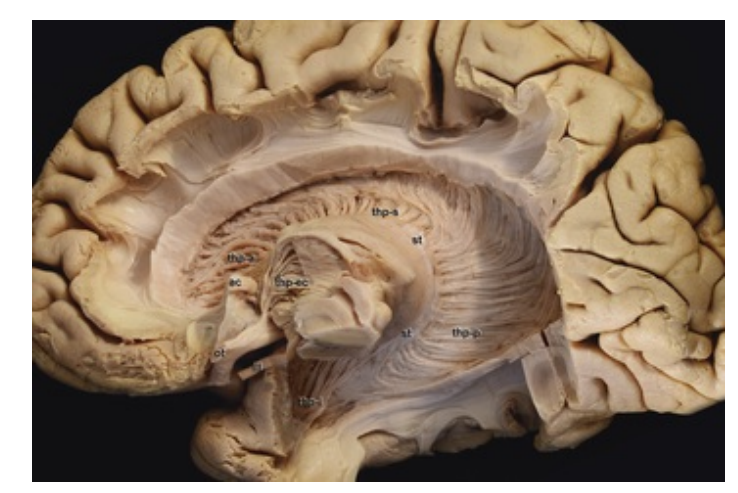

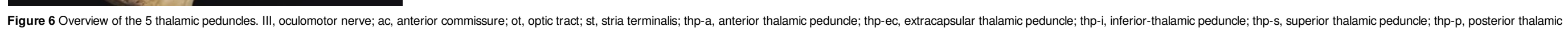
peduncle.

\section{Posterior Aspect}

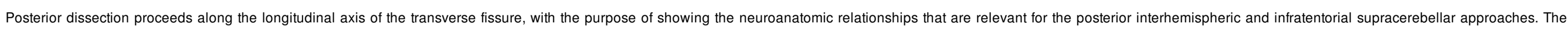

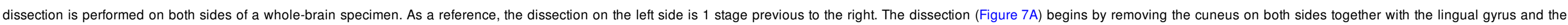

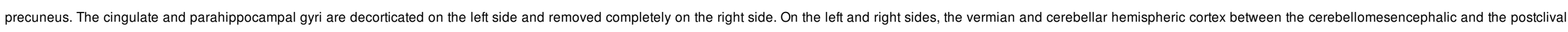

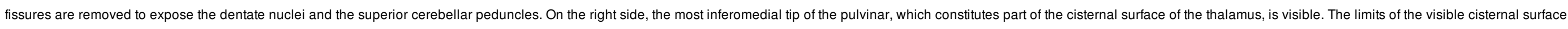
at this stage are defined by the splenium of the corpus callosum superiorly, the fimbria of the hippocampus laterally, the collicular brachii and the crus cerebri inferiorly, and the pretectum inferomedially (Figure $7 \mathrm{~A}$ ). 

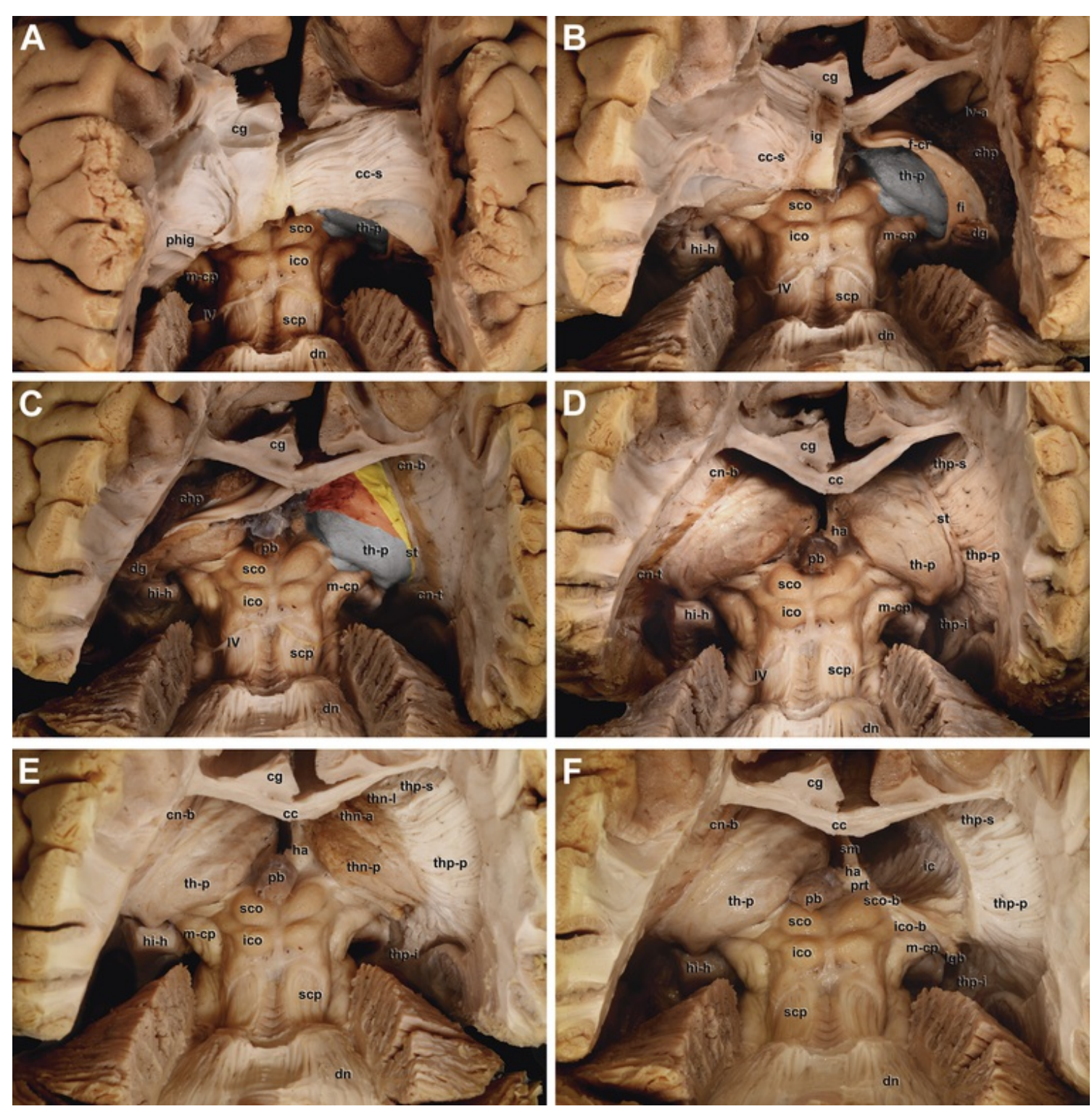

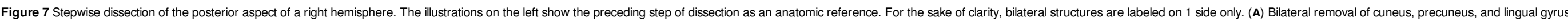

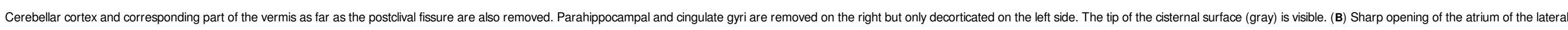

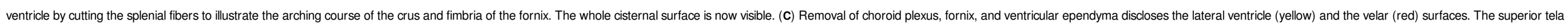

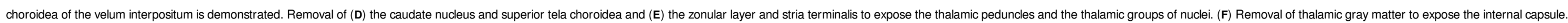

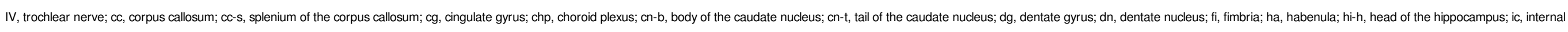

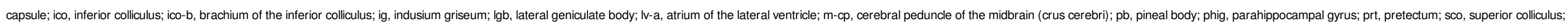

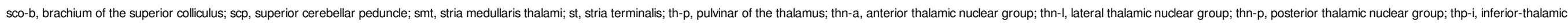




\section{elsevier_WNEU_4641}

peduncle; thp-s, superior thalamic peduncle; thp-p, posterior thalamic peduncle.

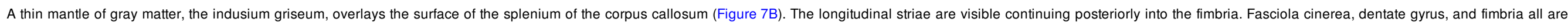

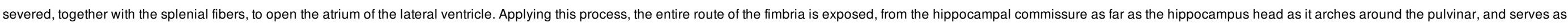
a separation between the cisternal and lateral ventricle surfaces of the thalamus.

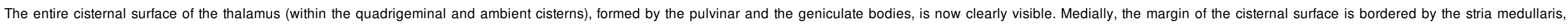

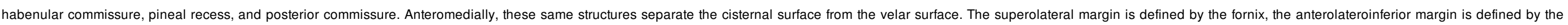
medial curve of the head of the hippocampus, and the inferior margin is defined by the brachii of the superior and inferior colliculi and the crus cerebri.

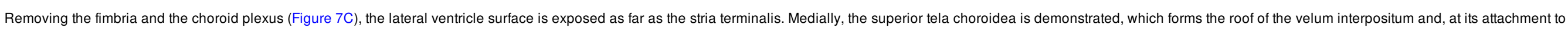

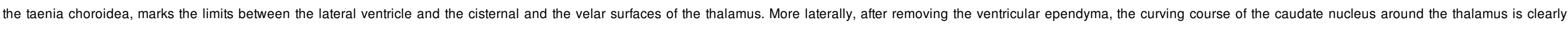

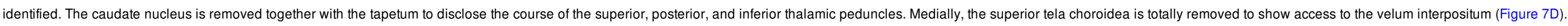

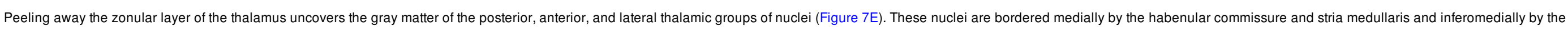
pretectal area and the brachii of the superior and inferior colliculi. Laterally, the fibers of the thalamic peduncles emerge from the thalamic gray matter to course laterally into the internal capsule (Figure 7F).

\section{Surgically Accessible Surfaces of the Thalamus}

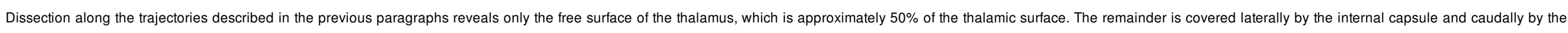

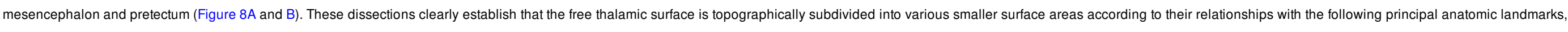

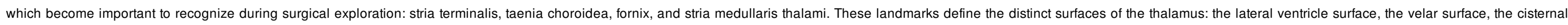
surface, and the third ventricle surface (Figure 9A-C).

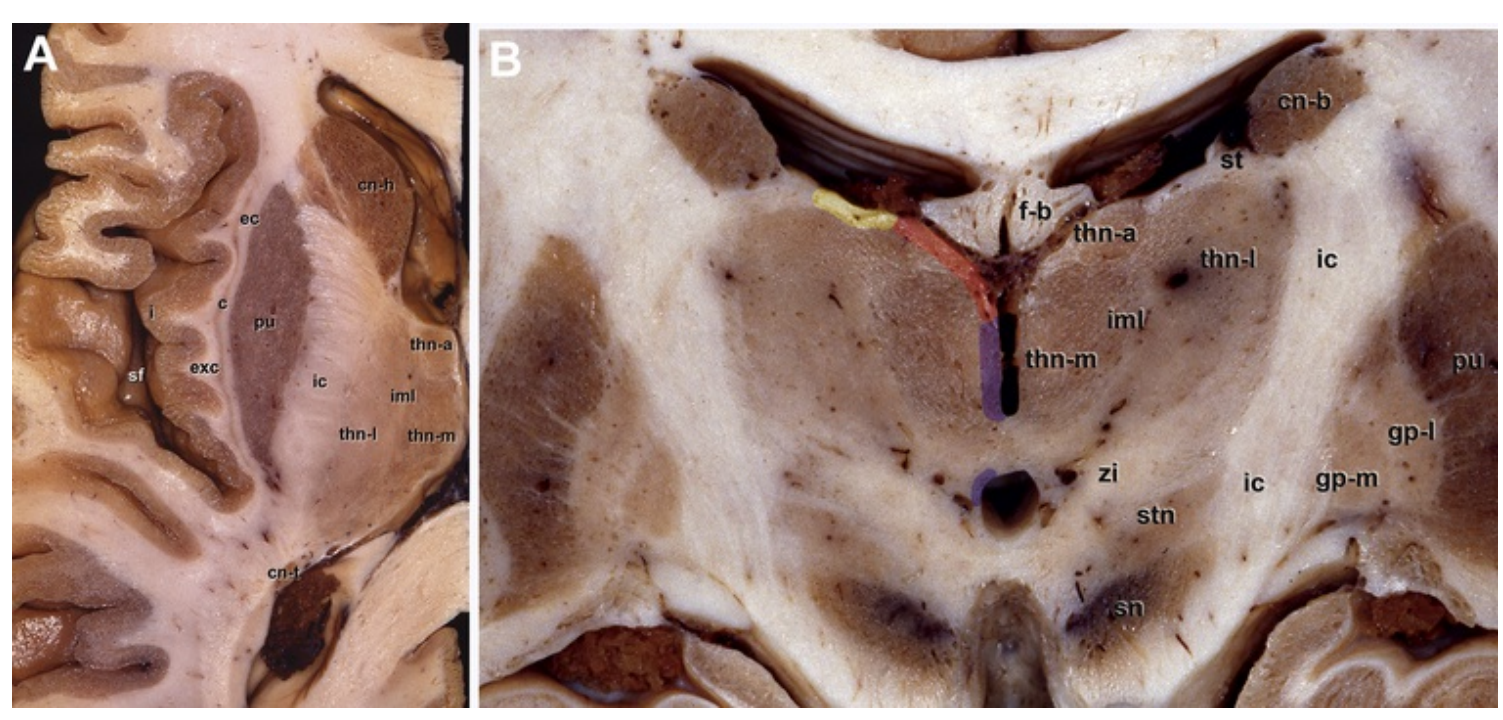

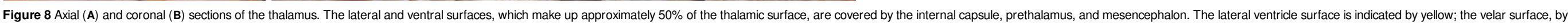

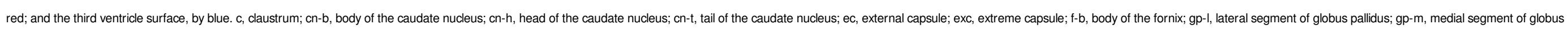

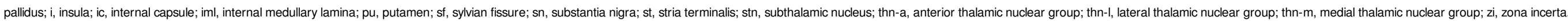




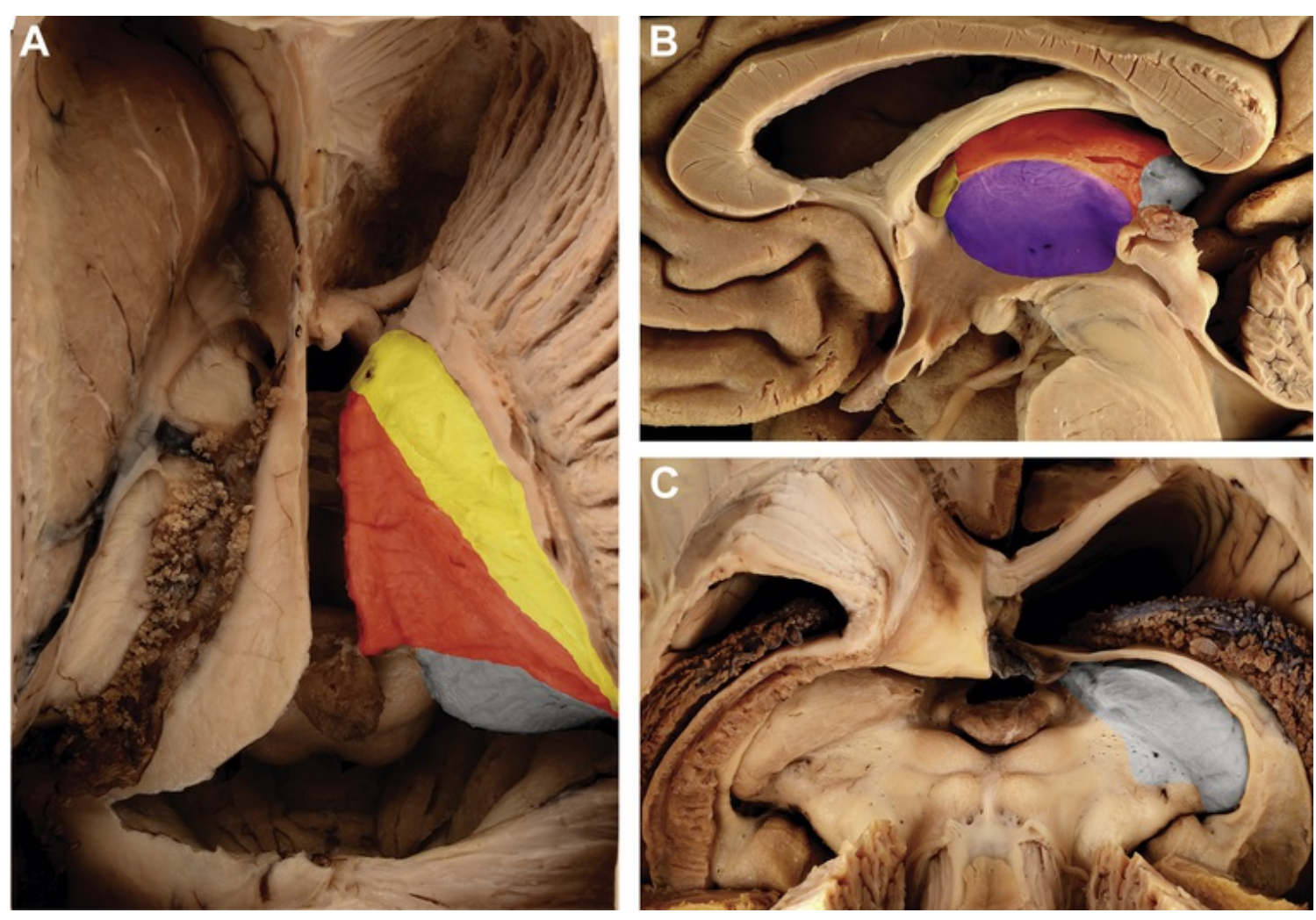

Figure 9 The free thalamic surfaces as visible from superior (A), medial (B), and posterior (C) views. The lateral ventricle surface is indicated by yellow; the velar surface, by red; the cisternal surface, by gray; and the third ventricle surface, by blue

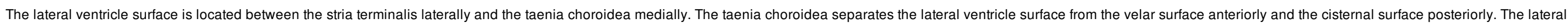

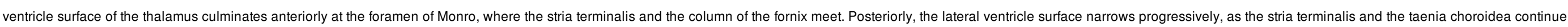

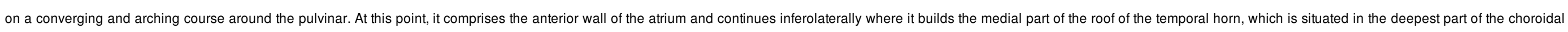
fissure where the stria terminalis and fimbria meet a short distance before the inferior choroidal point.

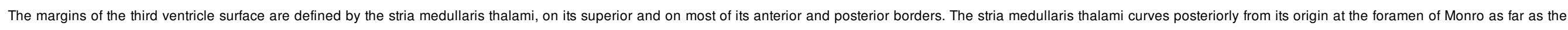

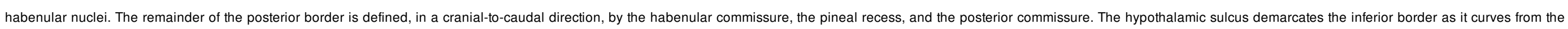
superior extremity of the cerebral aqueduct to the foramen of Monro.

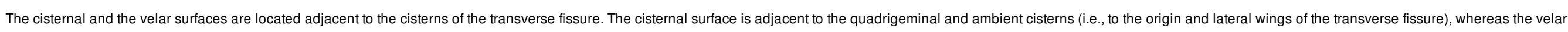

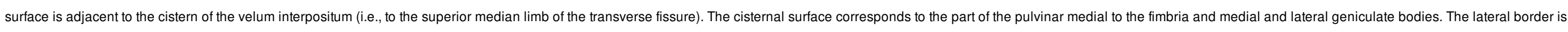

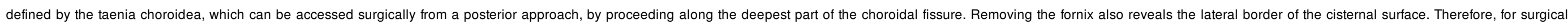

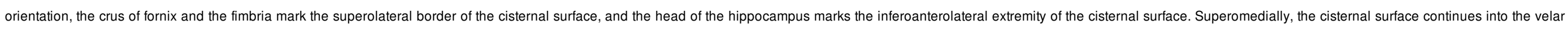

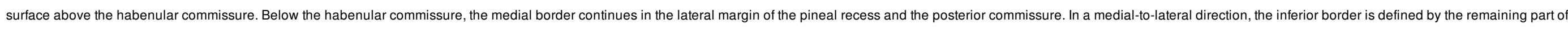
the pretectal area, the brachii of the superior and inferior colliculi, and, more laterally, the crus cerebri. The anteroinferior border is defined by the anterior limit of the lateral geniculate body.

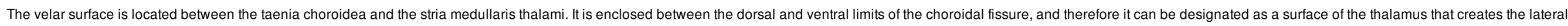

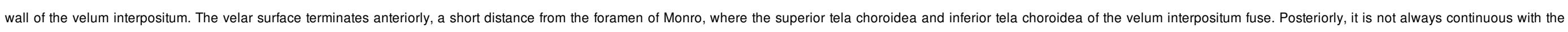


In our specimens, the third ventricle surface was always the largest, followed by the cisternal and velar surfaces. The lateral ventricular surface, which in every specimen was very narrow, was the smallest in all cases.

\section{Discussion}

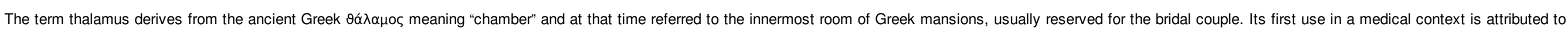

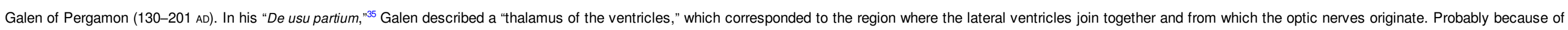

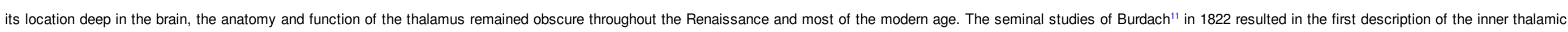

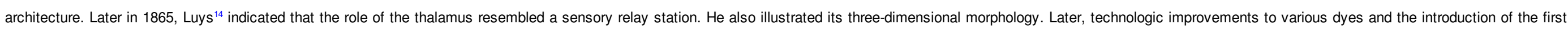

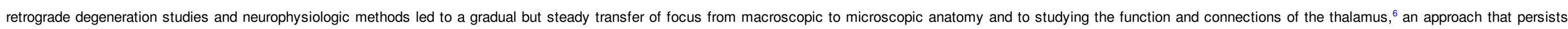

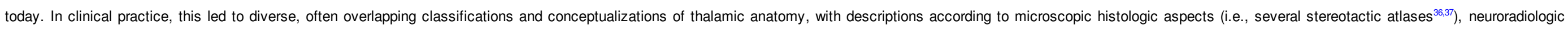
views $^{38}$ (including probabilistic parcellation ${ }^{39}$ and high-field visualization ${ }^{40,41}$ ), and neurophysiologic perspectives. ${ }^{6}$

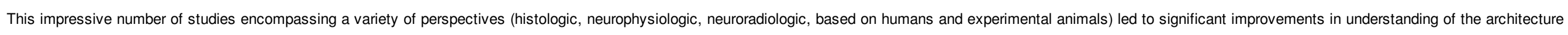

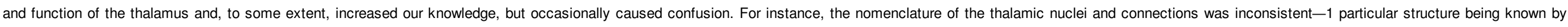

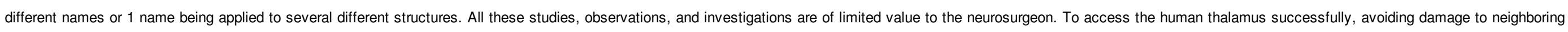
neural tissue, a detailed, illustrated description of the human thalamus topography and surrounding neural anatomy is decisive.

\section{Nomenclature Quandary}

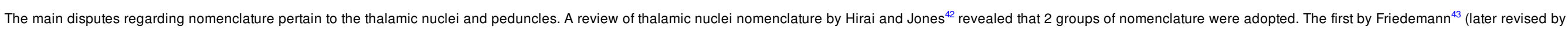

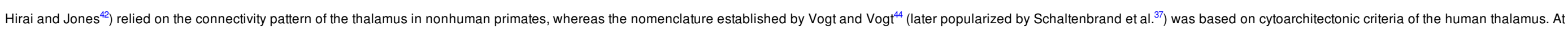
the present time, a process of seeking a unifying nomenclature that encompasses both cytoarchitectonic and connectivity patterns is in progress, a concept adopted in the present study. ${ }^{36,45}$

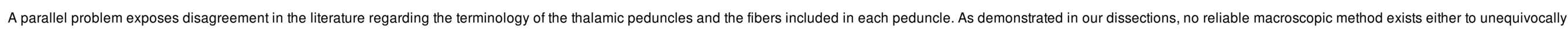

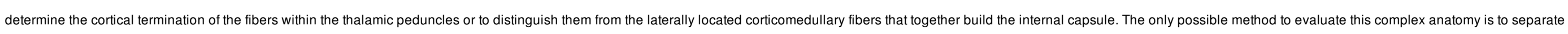
the fibers into segments according to their orientation, a method that we implemented in our study.

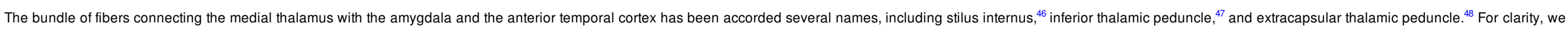

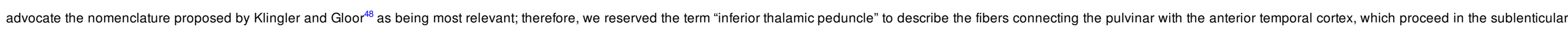

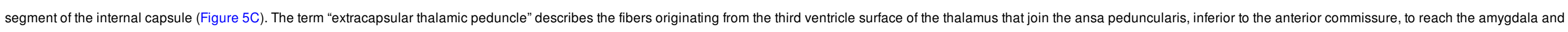

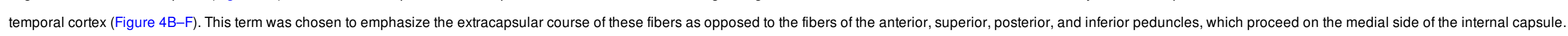

\section{Topographic Classification of Surgical Surfaces of the Thalamus}

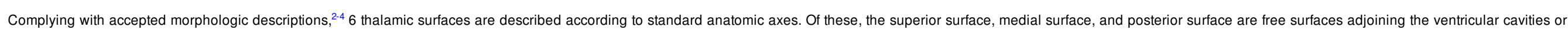

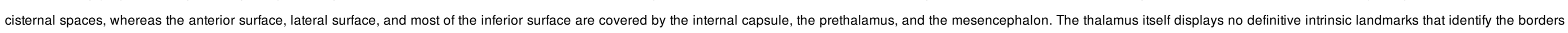

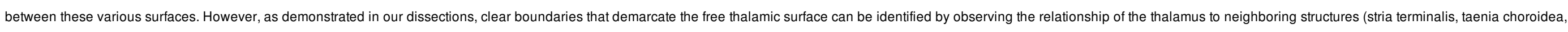
fornix, and stria medullaris thalami). Thus, the free surface has been divided into 4 areas: lateral ventricle surface, velar surface, cisternal surface, and third ventricle surface.

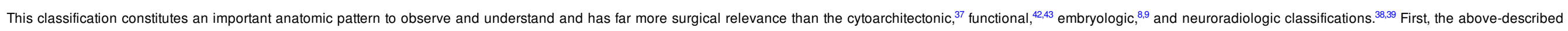

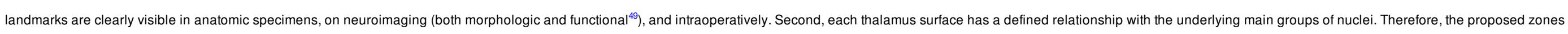

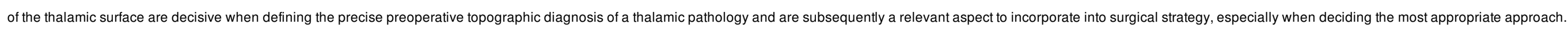




\section{Surgical Approaches to the Thalamus}

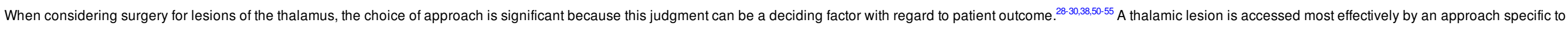

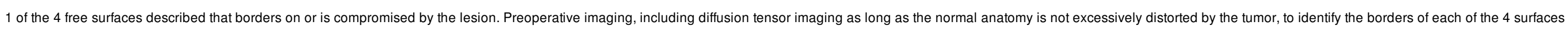
relative to the targeted lesion.

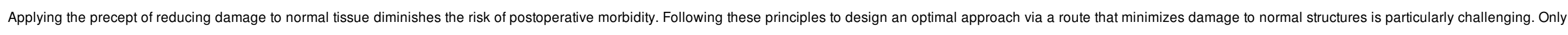

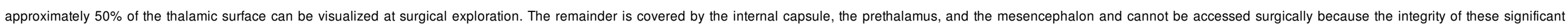
structures would be disrupted.

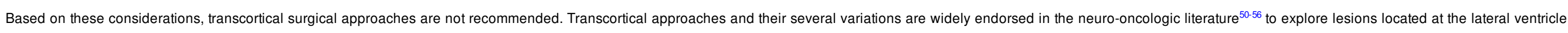

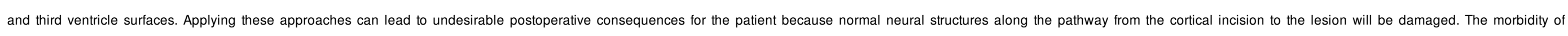
transcortical approaches for thalamic lesions (e.g., hemiparesis, hemianopia) is evident and well documented in the literature. ${ }^{51,52,54,55}$ The risk of epileptogenicity resulting from transcortical approaches is not negligible. ${ }^{57}$

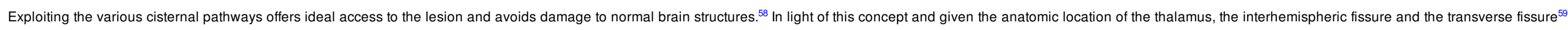

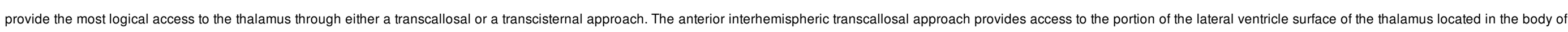

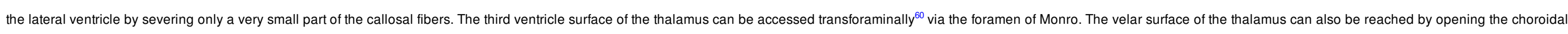

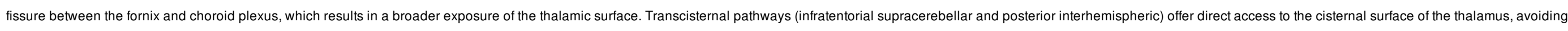
damage to any neural structures.

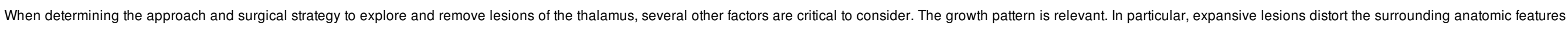

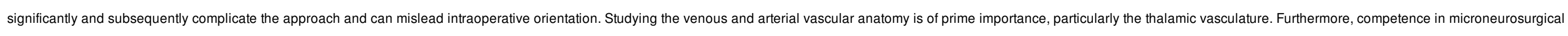
techniques and a detailed knowledge of brain anatomy as applied to neurosurgery are fundamental and essential prerequisites before pursuing surgery for lesions of the thalamus.

\section{Conclusions}

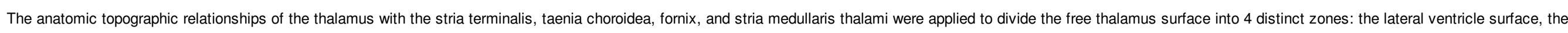

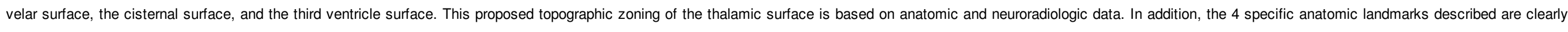

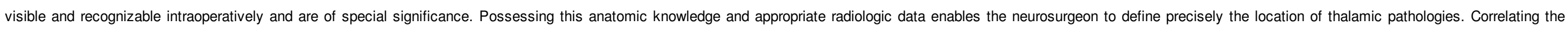
anatomic, radiologic, and surgical principles discussed in this article can guide and support the planning of the most appropriate and balanced surgical strategy.

\section{Acknowledgments}

The authors thank Julie Yamamoto for editorial assistance.

\section{References}

1

. E. Pernkopf and H.R. Ferner, Atlas of Topographical and Applied Human Anatomy: Head and Neck, 1963, WB Saunders Company; Philadelphia, PA.

2

.S. Standring and N.R. Borley, Gray's Anatomy: The Anatomical Basis of Clinical Practice, 40th ed., 2008, Churchill Livingstone; Edinburgh, UK.

3

. R. Nieuwenhuys, J. Voogd and C. van Huijzen, The Human Central Nervous System: A Synopsis and Atlas, 2007, Springer; Heidelburg, Germany. 


\section{elsevier_WNEU_4641}

. A. Parent and M.B. Carpenter, Carpenter's Human Neuroanatomy, 9th ed., 1996, Williams \& Wilkins; Baltimore, MD, 633-709.

5

. H.A. Riley, An Atlas of the Basal Ganglia, Brain Stem and Spinal Cord: Based on Myelin-stained Material, 1943, Williams \& Wilkins; Baltimore, MD.

6

E.G. Jones, The Thalamus 2 Volume Set, 2007, Cambridge University Press; Cambridge, UK.

7

. J.K. Mai and G. Paxinos, The Human Nervous System, 3rd ed., 2011, Academic Press; London, UK.

8

. C.J. Herrick, The morphology of the forebrain in amphibia and reptilia, Journal of Comparative Neurology and Psychology 20, 1910, 413-547.

9

. L. Puelles and J.L. Rubenstein, Forebrain gene expression domains and the evolving prosomeric model, Trends Neurosci 26, 2003, 469-476.

10

. C. Watson, G. Paxinos and L. Puelles, The Mouse Nervous System, 2011, Academic Press; London, UK.

11

. K.F. Burdach, Vom Baue und Leben des Gehirns, 1822, Dyk, 162-181.

12

. Meynert T. Psychiatrie; Klinik der Erkrankungen des Vorderhirns begruendet auf dessen Bau, Leistungen und Ernaehrung. Braumueller; $1884: 1-125$.

13

Foville AL. Traité complet de l'anatomie, de la physiologie et de la pathologie du système nerveux cérébro-spinal: 1. ptie., Anatomie. Fortin, Masson; 1844.

14

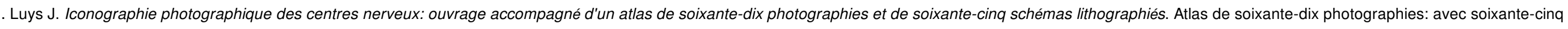
lithographiés. Baillière; 1873.

15

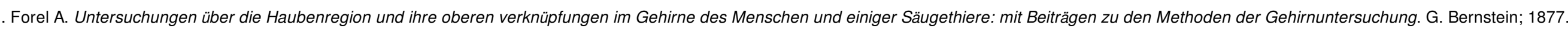

\section{6}

. J.D. Schmahmann and D. Pandya, Fiber Pathways of the Brain, 2009, Oxford University Press; New York, NY.

17

.W.J.S. Krieg and M. Mark, Architectonics of Human Cerebral Fiber Systems, 1973, Brain Books; Evanston, IL.

18

. Wolf-Heidegger G. Atlas der systematischen Anatomie des Menschen: Systema nervorum; Vasa sanguinea et lymphatica. Vol. III. Basel: Karger; 1962.

19

. A.L. Rhoton, Jr., The lateral and third ventricles, Neurosurgery 51 (4 suppl), 2002, S207-S271. 


\section{elsevier_WNEU_4641}

20

A.L. Rhoton, Jr., The cerebrum, Neurosurgery 51 (4 suppl), 2002, S1-S51.

21

. M. Bernstein, H.J. Hoffman, W.C. Halliday, E.B. Hendrick and R.P. Humphreys, Thalamic tumors in children. Long-term follow-up and treatment guidelines, $J$ Neurosurg $61,1984,649-656$.

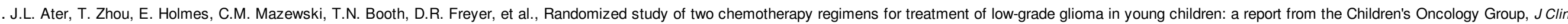
Oncol 30, 2012, 2641-2647.

23

. A.T. Reddy and R.J. Packer, Chemotherapy for low-grade gliomas, Childs Nerv Syst 15, 1999, 506-513.

24

. J. Boethius, E. Ulfarsson, T. Rahn and B. Lippittz, Gamma knife radiosurgery for pilocytic astrocytomas, J Neurosurg 97 (5 suppl), 2002, 677-680.

25

C.G. Hadjipanayis, D. Kondziolka, J.C. Flickinger and L.D. Lunsford, The role of stereotactic radiosurgery for low-grade astrocytomas, Neurosurg Focus 14, 2003 , e15.

26

N. Sanai, M.Y. Polley, M.W. McDermott, A.T. Parsa and M.S. Berger, An extent of resection threshold for newly diagnosed glioblastomas, J Neurosurg 115, 2011, 3-8.

.C. Arseni, Tumors of the basal ganglia; their surgical treatment, AMA Arch Neurol Psychiatry 80, 1958, 18-24.

. J. Greenwood, Jr., Radical surgery of tumors of the thalamus, hypothalamus, and third ventricle area, Surg Neurol 1, 1973, 29-33.

29

. M.G. Yaşargil, M. Curcic and C.D. Abernathey, Microneurosurgery: Microneurosurgery of CNS Tumors Vol. IVB, 1996, Georg Thieme Verlag; Stuttgart, Germany.

30

. M.G. Yaşargil, Microneurosurgery Vol. IVA, 1994, Thieme; Stuttgart, Germany, 139-141.

31

. J. Klingler, Erleichterung der makroskopischen Praeparation des Gehirns durch den Gefrierprozess, Schweiz Arch Neurol Psychiatr 1935, 247-256.

32

E. Ludwik and J. Klingler, Atlas Cerebri Humani/der Inner Ban Des Gehirns/the Inner Structure of the Brain/la Structure Interne Du Cerveau/la Arquitectura Interna Del Cerebro, 1956, Little, Brown; Boston, MA.

33

U. Türe, M.G. Yasargil, A.H. Friedman and O. Al-Mefty, Fiber dissection technique: lateral aspect of the brain, Neurosurgery 47, 2000, 417-426, [discussion: 426-427].

Galenus. De usu partium corporis humani libri XVII. Basilea: Apud Gulielmum Rovillium; 1533. 


\section{elsevier_WNEU_4641}

36

A. Morel, M. Magnin and D. Jeanmonod, Multiarchitectonic and stereotactic atlas of the human thalamus, J Comp Neuro/ 387, 1997, 588-630.

37

G. Schaltenbrand, R.G. Hassler and W. Wahren, Atlas for Stereotaxy of the Human Brain, 1977, Thieme; Stuttgart, Germany.

38

. L. Rangel-Castilla and R.F. Spetzler, The 6 thalamic regions: surgical approaches to thalamic cavernous malformations, operative results, and clinical outcomes, J Neurosurg 123, $2015,676-685$.

39

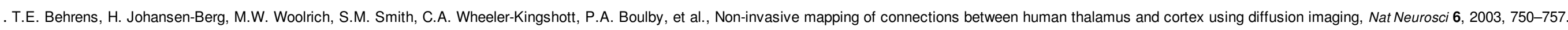

40

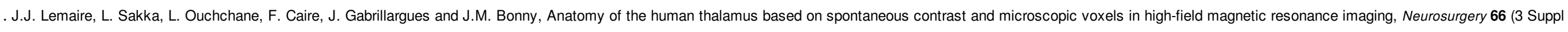
Operative), 2010, 161-172.

41

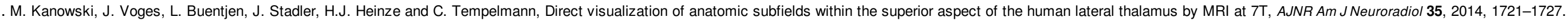
42

T. Hirai and E.G. Jones, A new parcellation of the human thalamus on the basis of histochemical staining, Brain Res Brain Res Rev 14, $1989,1-34$.

43

. Friedemann M. Die Cytoarchitektonik des Zwischenhirns der Cercopitheken mit besonderer Berücksichtigung des Thalamus opticus. J.A. Barth; 1911.

44

. O. Vogt and C. Vogt, Thalamusstudien I-III, J Psychol Neurol 50, 1941, 31-154.

45

. G. Macchi and E.G. Jones, Toward an agreement on terminology of nuclear and subnuclear divisions of the motor thalamus, J Neurosurg 86, 1997, 670-685.

46

. Meynert T. Psychiatrie: klinik der Erkrankungen des Vorderhirns begründet auf dessen Bau, Leistungen und Ernährung. Wien: W. Braumüller; 1884.

47

. S. Ranson, A description of some dissections of the internal capsule, the corona radiata and the thalamic radiation to the temporal lobe, Archives of Neurology \& Psychiatry 5, $1921,361-369$.

48

. J. Klingler and P. Gloor, The connections of the amygdala and of the anterior temporal cortex in the human brain, J Comp Neurol 115, 1960, 333-369.

49

. S. Mori, S. Wakana, P.C.M. van Zijl and L.M. Nagae-Poetscher, MRI Atlas of Human White Matter, 2005, Elsevier; Amsterdam, Netherlands.

50

. B. Bilginer, F. Narin, I. Isikay, K.K. Oguz, F. Soylemezoglu and N. Akalan, Thalamic tumors in children, Childs Nerv Syst 30, 2014, 1493-1498.

51 


\section{elsevier_WNEU_4641}

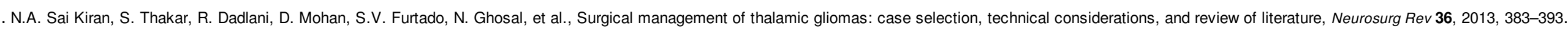

52

. M. Baroncini, M. Vinchon, J.F. Mineo, F. Pichon, J.P. Francke and P. Dhellemmes, Surgical resection of thalamic tumors in children: approaches and clinical results, Childs Nerv Syst 23, 2007, 753-760.

53

. V. Cuccia and J. Monges, Thalamic tumors in children, Childs Nerv Syst 13, 1997, 514-520, [discussion: 521].

54

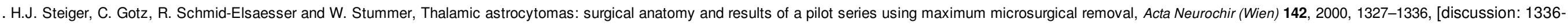
1337].

55

. Y.A. Moshel, M.J. Link and P.J. Kelly, Stereotactic volumetric resection of thalamic pilocytic astrocytomas, Neurosurgery 61, 2007, 66-75, [discussion: 75].

\section{6}

. A.L. Albright, Feasibility and advisability of resections of thalamic tumors in pediatric patients, J Neurosurg 100 (5 Suppl Pediatrics), $2004,468-472$.

57

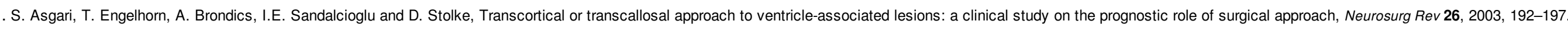
58

. Harput M, Türe U. Microneurosurgical removal of a posterior thalamic glioma via posterior interhemispheric subsplenial approach in lateral oblique position. In press.

59

. M.G. Yasargil, Microneurosurgery Vol. IIIA, 1987, Thieme; Stuttgart, Germany, 296-303.

60

. U. Türe, M.G. Yasargil and O. Al-Mefty, The transcallosal-transforaminal approach to the third ventricle with regard to the venous variations in this region, $J$ Neurosurg $87,1997,706-715$.

\section{Queries and Answers}

Query: If there are any drug dosages in your article, please verify them and indicate that you have done so by initialing this query

Answer: there are no drug dosage in the article

Query: In article title, OK to change "Thalamus" to the adjective form "Thalamic" before "Surfaces"?

Answer: If possible we'd like to keep "Thalamus surface"

Query: Is the last sentence of Abstract, "These proposed surface divisions, based on recognizable anatomic landmarks, can provide more reliable surgical orientation," OK as edited?

Answer: ok as edited

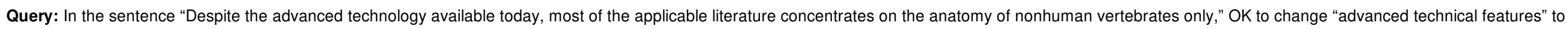
"advanced technology"?

Answer: ok as edited

Query: Is the sentence "A comprehensive knowledge of anatomy is essential to successfully performing precise microneurosurgical procedures" OK as edited?

Answer: ok as edited 


\section{elsevier_WNEU_4641}

Query: In the text "These fibers are also known as the stria longitudinalis medialis corporis callosi (or stria of Lanci)," are changes in stria names OK per Dorland's?

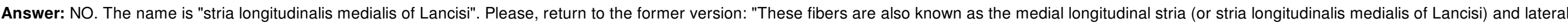
longitudinal stria."

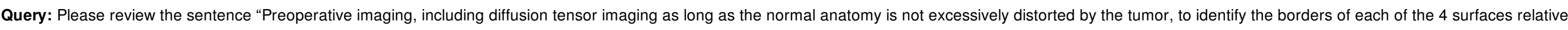
to the targeted lesion." A verb is needed before "to identify."

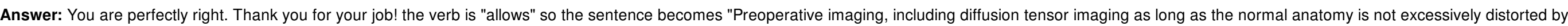
the tumor, ALLOWS to identify the borders of each of the 4 surfaces relative to the targeted lesion."

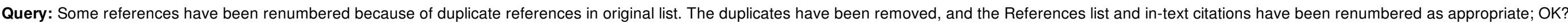
Answer: ok, thank you

Query: Please provide abbreviated journal name for ref. 8. I couldn't found it on pubmed.

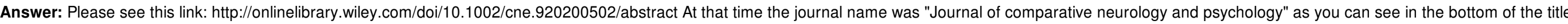

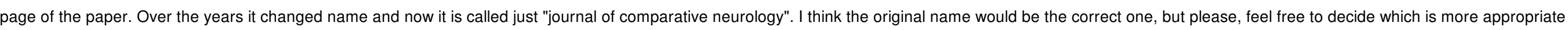

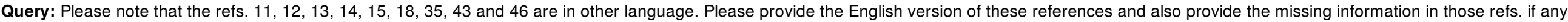

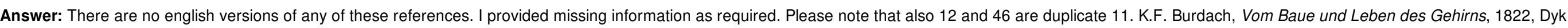

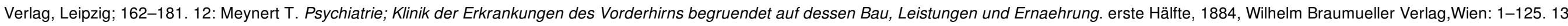

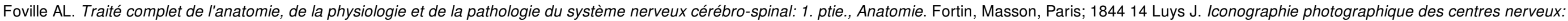

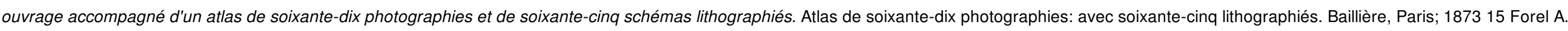

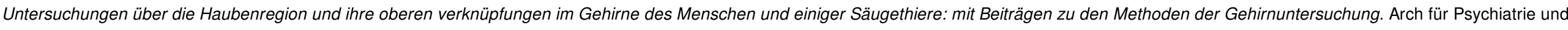

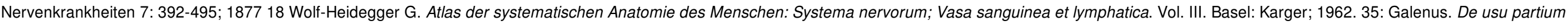

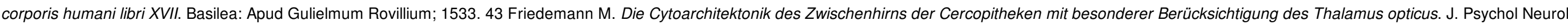
18: 309-378 (1911) 46 Meynert T. Psychiatrie; Klinik der Erkrankungen des Vorderhirns begruendet auf dessen Bau, Leistungen und Ernaehrung. 1884, Wilhelm Braumueller Verlag, Wien: 1-125.

Query: Please check the volume number in refs. 29 and 30, 46 and correct if necessary.

Answer: 29: IVB is correct 30: IVA is correct 46: has been corrected. It is vol 1 which in german is "erste hälfte"

Query: Please provide abbreviated journal title for ref. 47.

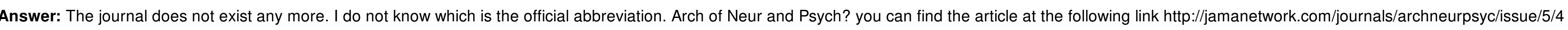

Query: For reference 58 (Harput and Türe), please provide complete updated details regarding publication status; if still in press, please provide journal title.

Answer: The ref 58 is still in press by "Neurosurgery"

Query: Please confirm your conflict of interest statement is correct.

Answer: correct

Query: Is a credit line from a previously published source needed for Figure 1? If yes, please provide complete credit line and submit written permission when returning your author proof.

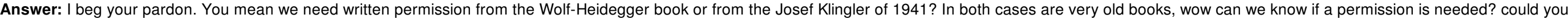
help us? 


\section{elsevier_WNEU_4641}

Query: In Figure 2 legend text "fiber tracts pertaining to the thalamic radiations are represented with square sections," OK to replace "those" with "fiber tracts"?

Answer: ok! thank you

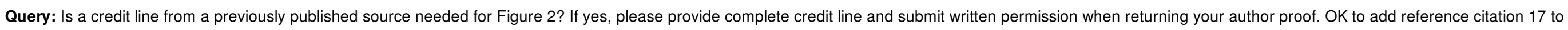
legend where book title is mentioned? Is the source for Figure 2 Krieg and Mark?

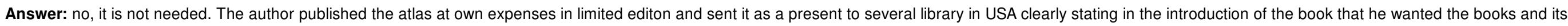
content to be freely available to anyboby

Query: Is Table 1 title OK as added? and also check the layout.

Answer: ok

Query: In Table 1, are abbreviations STN and SN correctly spelled out in footnote?

Answer: yes

Query: Please provide volume number if any for ref. 31.

Answer: volume 36. Thanks for your checking

Query: Refs. 12 and 46 are found to be identical with slight variation in page range. Please check and amend if necessary.

Answer: Amended (please see answer to query 10)

Query: Please confirm that given names and surnames have been identified correctly.

Answer: correct 